NBER WORKING PAPERS SERIES

\title{
MONETARY POLICY, BUSINESS CYCLES AND THE BEHAVIOR OF SMALL MANUFACTURING FIRMS
}

\author{
Mark Gertler
}

Simon Gilchrist

Working Paper No. 3892

\author{
NATIONAL BUREAU OF ECONOMIC RESEARCH \\ 1050 Massachusetts Avenue \\ Cambridge, MA 02138 \\ November 1991
}

Thanks to Jim Hamilton, Anil Kashyap, and seminar participants at Northwestern and Yale Universities for helpful conments. This paper is part of NBER's research program in Monetary Economics. Any opinions expressed are those of the authors and not those of the Federal Reserve Board or the National Bureau of Economic Research. 
NBER Working Paper $\$ 3892$

November 1991

\author{
MONETARY POLICY, BUSINESS CYCLES \\ AND THE BEHAVIOR OF SMALL MANUFACTURING FIRMS
}

\title{
ABSTRACT
}

We present evidence on the cyclical behavior of small versus large manufacturing firms, and on the response of the two classes of firms to monetary policy. Our goal is to take a step toward quantifying the role of credit market imperfections in the business cycle and in the monetary transmission mechanism. We find that, following tight money, small firms sales decline at a faster pace than large firm sales for a period of more than two years. Further, bank lending to small firms contracts, while it actually rises for large firms. Monetary policy indicators tied to the performance of banking, such as M2, have relatively greater predictive power for small firms than for large. Finally, small firms are more sensitive than are large to lagged movements in GNP. Considering that small firms overall are a non-trivial component of the economy, we interpret these results as suggestive of the macroeconomic relevance of credit market imperfections.

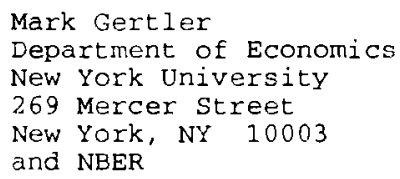

Simon Gilchrist Research and Statistics Federal Reserve Board Washington, DC 20551 


\section{Introduction}

This paper presents evidence on the cyclical behavior of small versus large manufacturing firms, and on the differential response of the two kinds of firms to various indicators of monetary policy. Our objective is to provide some empirical insight into the role of credit market imperfections in the monetary transmission mechanism and in the business cycle, more broadly. Subject to the usual caveats of interpreting time series results, our principal findings are that small firms react more sharply and typically quicker both to movements in GNP and to movements in conventional indicators of monetary policy. As we will argue, our empirical findings, in conjunction with the fact that small firms are a non-trivial component of GNP, are suggestive of the macroeconomic relevance of credit market frictions.

There is a large body of evidence consistent with the idea that monetary policy has been an important factor in postwar business fluctuations (e.g., Sims (1980), Eckstein and Sinai (1986), Romer and Romer (1989), Bernanke and Blinder (1990)). There remains, however, considerable debate over the exact nature of the monetary transmission mechanism. One element of this debate is whether credit market imperfections may enhance the potency of monetary policy (e.g., Blinder and Stiglitz (1983), Romer and Romer (1990), Bernanke and Blinder (1990), Kashyap, Wilcox and Stein (1991)). Efforts to resolve this issue have concentrated on analyzing the response of various money and credit aggregates to shifts in monetary policy. Though this approach has been informative, one limitation is that the competing theories are of ten capable of generating similar predictions about the movement of money and credit. This observational equivalence 
problem arises because it is typically difficult to distinguish between

demand versus supply-induced movements of each financial aggregate. ${ }^{1}$ We try to shed light on the issue in an alternative way, by comparing the cyclical behavior of small versus large firms. Our approach exploits the idea that small firms are more likely to confront credit market frictions. ${ }^{2}$

Section 2 presents a simple model designed to illustrate how credit market imperfections may introduce a kind of risk aversion on the part of firms, making their behavior "excessively sensitive" to earnings flows and to interest rates. ${ }^{3}$ The model also predicts that these magnification effects are likely to be proportionately greater the smaller the firm. The model thus suggests, everything else equal, that small firms should be more sensitive than large firms to macroeconomic conditions. Macroeconomic conditions include both the state of the business cycle and the stance of monetary policy, under the interpretation that changes in the short term interest rate encapsulate shifts in monetary policy. It is worth adding that our story is complementary but not isomorphic to the "credit view" of

${ }^{1}$ There have been some creative approaches to solving the identification problem. Kashyap, Wilcox and Stein (1991), for example, try to identify shifts in credit supply by examining the behavior of the division of short term credit between bank loans and commercial paper, and then demonstrating the relationship of this "mix" variable to real activity.

${ }^{2}$ Differential effects on small versus large firms has been an important theme of the empirical literature on credit market imperfections and investment. See, for example, Fazzari, Hubbard and Peterson (1988) and Evans and Jovanovic (1989). The macroeconomic consequences are discussed in Gertler and Hubbard (1989).

${ }^{3}$ This kind of excess sensitivity result is a key feature of the literature on the macroeconomic consequences of credit market imperfections. See, for example, Farmer (1985), Williamson (1987), Greenwald and Stiglitz (1988), Bernanke and Gertler (1989) and Gertler (forthcoming). 
monetary policy, as articulated by Blinder and Stiglitz (1983) and Bernanke and Blinder (1988); this is because our theory relies on magnification effects owing to credit market imperfections rather than on the ability of monetary policy to directly regulate bank lending."

We check the general implications of our model by analyzing the time series behavior of small versus large firms. Section 3 describes the data set we use. It consists of a time series of sales by manufacturing firms, divided up by size class. We present some summary statistics to indicate how relative importance and cyclical behavior varies by size class. Section 4 presents an analysis of this data within a set of time series models that include GNP and one or more indicators of monetary policy. The models allow for interactive effects between large and small firms in order to help identify the true independent impact of the macroeconomic variables.

Perhaps our main empirical result is that small firms are indeed more sensitive to shifts in monetary policy. We employ two different methods to capture exogenous shifts in monetary policy, and find that the result holds in both cases. We first use innovations in the federal funds rate, as suggested by Bernanke and Blinder (1990); and then consider the dummy variables for shifts to tight money that Romer and Romer (1989) constructed. The differential response of small firms is particularly striking when the Romer dummies are used. Relatedly, we find that in the wake of tight money,

\footnotetext{
${ }^{4}$ Romer and Romer (1990) have criticized the credit view, arguing that because reserve requirements on $C D s$ are low (now they no longer exist), monetary policy cannot effectively regulate the flow of bank lending. (The argument presumes that banks are able to elastically issue CDs, which is open to debate.) Whether our theory is right, however, is not tied to the question of whether open market operations directly control bank credit.
} 
bank lending to small firms contracts, while it rises for large firms. Additionally, small firms are more sensitive to lagged movements in GNP, which is consistent with our theory.

We also explore the partial correlations of small and large firms with the various monetary policy indicators. Several results here deserve highlighting: Small firms are more closely related than large firms to $\mathrm{M} 2$ and to the ratio of bank loans to commercial paper (the "mix" variable constructed by Kashyap, Stein and Wilcox (1991) to capture the tightness of monetary policy); Conversely, the commercial paper/ T-bill risk-spread is a better predictor of large firm behavior. Financial aggregates connected with banking - M2 and the mix variable - are thus relatively more informative about small firm behavior, while the financial aggregate most directly connected with conditions in the commercial paper market - the risk spread - is most informative about large firm behavior. We show further that the current recession conforms to this pattern (and indeed exhibits symptoms of involving a credit crunch on small firms). Concluding remarks are in section 5 .

\section{Theory}

In this section we present a simple model designed to illustrate how credit market imperfections may amplify the impact of macroeconomic disturbances, including shifts in interest rates, technology and demand. An important prediction is that the magnification effect is stronger in percentage terms the smaller the firm. The basic framework is a variation of Townsend's (1979) costly state verification model. The key difference is the addition of a variable input which may be thought of either as labor, or 
perhaps as an intermediate input. ${ }^{5}$ This modification allows us to study fluctuations in firm output.

There are two periods: 0 and $1 .{ }^{b}$ A risk-neutral firm has a technology which takes input $\mathrm{x}$ in period 0 and yields a random quantity of output $\mathrm{y}$ in period 1. It costs $(1 / 2) x^{2}$ to obtain $x$ units of input. Output in period 1 is given by $\tilde{y}=\tilde{\omega} \cdot 2 \theta x$. The random variable $\tilde{\omega}$ is distributed continuously and uniformly over the unit interval. Therefore: $E\{\tilde{y} \mid \mathbf{x}\}=\theta x ; \operatorname{pr}\{\tilde{\omega} \geq \omega\}$ $E H(\omega)=\omega$; and $\partial H(\omega) / \partial \omega=1$. The realization of $\tilde{\omega}$ is independent of events elsewhere in the economy; that is, $\tilde{\omega}$ is idiosyncratic to the firm.

The parameter $\theta$ is a composite of a technology factor, $\psi$. which is common across firms, and a scale parameter, $\lambda$, meant to reflect the size of the firm:

$$
\theta=\psi \cdot \lambda
$$

$\lambda$ reflects the stock of fixed factors; a larger value of $\lambda$ raises the expected marginal product of the variable factor, $\theta$ may thus vary across firms owing to differences in $\lambda$. Time series movements in $\theta$, however, are due to the common shock, and are therefore perfectly correlated across firms. Think of the common productivity shock as a random variable with a realized value $\psi$ that becomes known prior to the choice of $x$. We may therefore treat $\psi$ as parameter in the firm's optimization problem, and may

\footnotetext{
${ }^{5}$ For applications of Townsend's costly state verification model to macroeconomics, see Gale and Hellwig (1985), Williamson (1987b), Bernanke and Gertler (1989), and Gilchrist (1990). The model of this paper is most closely related to Gilchrist's.

${ }^{6}$ For an extension of this kind of analysis to a dynamic environment, where borrowers and lenders may enter multiperiod arrangements, see Gertler. forthcoming.
} 
interpret shifts in $\psi$ as a technology or demand disturbance. ${ }^{7}$ For parsimony, we will suppress $\psi$ and $\lambda$, and instead carry around the composite parameter $\theta$. Shifts in $\theta$ therefore encompass technology shocks, while the relative level of $\theta$ reflects firm size.

Because there exists a lag in the production process, the firm must finance its input expenditure. In period 0 , it borrows funds from a risk-neutral competitive intermediary. The size of the loan, $b$, is given by

$$
b=(1 / 2) x^{2}
$$

The intermediary's opportunity cost of funds equals the gross riskless

interest rate, $r$, which we take as given. As with $\theta, r$ may be random so long as its value is known before the firm's choice of $\mathrm{x}$.

As in Townsend (1979), we assume the intermediary may not freely observe the firm's output. To do so, it must pay a fix cost $\gamma$. One may interpret $\gamma$ more generally as the cost of default. We incorporate scale economies in default costs by assuming that $\gamma$ is fixed even though the firm's size of operation is variable. ${ }^{8}$ We assume further that the ex post bankruptcy cost is less than the size of the loan the firm would obtain if there was no credit

That is, $\psi$ could either be a productivity parameter or a relative price. Shifts in $\psi$ are technology disturbances under the former interpretation and are demand shocks under the latter.

${ }^{8}$ The key assumption is that the expected average product is higher for large firms than for small firms (which makes the debt of the large firm safer). Having any kind of fixed cost will suffice. To minimize algebra, it is simplest to embed the scale economies in the bankruptcy costs, which in itself does not seem unreasonable.

Two alternative ways to obtain our predictions would be to assume that small firms face proportionately more idiosyncratic risk or to assume they have proportionately less collateral than large firms. Either assumption would generate a proportionately larger premium for external funds for small firms. 
market imperfection. This requires

$$
\gamma<(1 / 2) \cdot(\theta / r)^{2}
$$

where $(\theta / r)$ is the first-best value of $\mathbf{x}$. Equation (2) guarantees that the credit market friction induces under-investment relative to the first best.

As Townsend (1979), Gale and Hellwig (1985) and Williamson (1987a) show, under certain assumptions, the optimal financial contract is risky debt. $^{10}$ Define $d$ as the payment the firm promises to the intermediary. Whenever realized output, $\omega 2 \theta x$, is greater than or equal to $d$, the intermediary receives this payment and the firm gets to keep the residual, $\omega 2 \theta x-d$. If $\omega 2 \theta x$ is less than $d$, the firm defaults. The lender pays $\gamma$ and gets to keep all the realized output. The firm is left with nothing.

Since $\omega$ is distributed uniformly over the unit interval, the probability of default, p, equals the ratio of the promised payment to the maximum reasible value of output, $d / 2 \theta x$. Conditional on the choice of input $x, p$ must satisfy

$$
2 \theta x \cdot\left(p(1-p)+f^{e} \omega \cdot d \omega\right)-p \gamma=r b
$$

Equation (2) requires that the intermediary's expected return (the left side) equal its opportunity cost of funds, rb.

The firm's contracting/investment problem is to choose $x, b$ and $p$ to

'Without condition (2), it may pay for the firm to over-invest relative to the to the first-best optimum in order to exploit the scale economies in bankruptcy costs. This will become apparent in the subsequent analysis.

${ }^{10}$ The two required assumptions are: (i) only deterministic auditing schemes are reasible; and, (ii) the intermediary can commit to an auditing policy. Relaxing either of these assumptions does not affect our basic conclusions regarding the impact of the credit market distortions on firm variability. However, we maintain them in order to preserve tractability. 
maximize expected profits, $V(x, p)$, given by

$$
V(x, p)=\max \left\{\theta x-\theta x \cdot\left[p(1-p)+s^{+} \omega \cdot d \omega\right], \quad 0\right\}
$$

subject to equations 1 and 3 , and to the feasibility condition that it can never pay the intermediary more than realized output.

There are two kinds of outcomes. We call the first the "basic" case, and the second, the "rationing" case. In both situations, the credit market imperfection enhances the sensitivity of output to shifts in $\theta$ or $r$. Because the latter only emerges when the fixed bankruptcy cost is exceptionally large relative to the size of the firm, we concentrate most of our attention on the former. The case of rationing is deferred to the appendix.

\section{2a. Input Choice and Output Fluctuations in the Basic Case.}

The firm chooses input $x$ to satisf $y$

$$
\theta=r x+\gamma \cdot \frac{\partial p}{\partial x}
$$

where,

$$
\frac{\partial p}{\partial x}=\left(\frac{1}{2 \theta}\right) \frac{[r-(\gamma / b) \cdot p]}{2(1-p)-(\gamma / \theta x)}
$$

The left side of equation (5) is the expected marginal product of $\mathrm{x}$, and the right side is the expected marginal cost. The term $\gamma \cdot \frac{\partial p}{\partial x}$ is the rise in expected bankruptcy costs. $\frac{\partial p}{\partial x}>0$; as $x$ goes up, $p(=d / 2 \theta x)$ must rise to ensure that the intermediary receives a competitive return. ${ }^{11}$ The credit

\footnotetext{
${ }^{11}(\partial p / \partial x)$ is obtained by differentiating equation (3), the constraint that the intermediary must receive a competitive return. The denominator. $2(1-p)-(\gamma / \theta x)$, is the change in the intermediary's expected return given a rise in the non-default payment, divided by $\theta x$. In any optimum, this value must be non-negative. Otherwise the firm could gain by reducing $d$, and
} 
market imperfection thus increases marginal cost.

Figure 1 illustrates the outcome. The dd curve portrays the expected marginal product of $x$, which is fixed at $\theta$. The ss curve portrays the expected marginal cost. The dotted line plots the function $r x$, the marginal cost curre the firm would face in the absence of credit market frictions. The intersection of the dd curve with the dotted line accordingly defines the first best value of $x_{--}$call it $x^{*}$. The firm's optimal choice of $x$, however, is given by the intersection of the $d d$ and ss curves. The expected bankruptcy costs (measured by the gap between ss and the dotted line) reduce $x$ below $x^{\cdot 12}$ It is now apparent how the impact of the credit market distortion depends inversely on the size of the firm. Inspection of eqs. (5) and (6) illustrate that the expected bankruptcy costs become relatively less important with increases in $\theta$. There is a direct effect; the expected marginal product of $\mathbf{x}$ rises relative to the ex post bankruptcy cost. There is also an indirect effect. The rise in the average product reduces the marginal probability of bankruptcy. (Notice in eq. (6) that $\frac{\partial p}{\partial x}$ varies inversely with $\theta$, ceterus parabus.J

The credit market imperfections work to magnify the impact of shifts in any of the primitive parameters. Figure 2 portrays the effect of a change in

still offer the intermediary a competitive return. In the basic case, this value is positive at the optimum. The basic case arises, therefore, if the bankruptcy cost is not extremely large relative to mean output, and/or if the bankruptcy probability is not unreasonably large.

Condition (2) guarantees that the numerator is positive when $x$ equals its unconstrained optimal value $(\theta / r)$. This ensures that the resulting constrained optimum lies below the first best. See the analysis below. ${ }^{12}$ It may be verified that it is always profitable ex ante for the firm to operate in the basic case; i.e., expected profits are positive. 
$\theta$, which we now interpret as either a shift in technology or demand. A rise in $\theta$ not only lifts the dd curve. The supply curve also rotates outward, as the expected marginal bankruptcy costs decline. The key idea is that input choice depends not only on the net marginal product, but also on the average product which influences the expected average bankruptcy costs. A rise in the interest rate similarly has a magnified effect, as Figure 3

illustrates. ${ }^{13}$ The decline in average product raises the marginal bankruptcy costs, which enhances the inward shift of the supply curve. It may be verified formally that credit market imperfections raise the elasticity of $\mathbf{x}$ with respect to both $\theta$ and $r$. Since expected output is proportionate to input, the higher input elasticities translate into higher output. elasticities.

Monetary policy enters the picture to the extent it may be responsible for shifts in the riskless interest rate $r$. We may conclude, therefore, that the credit market imperfection magnifies the ultimate impact of monetary policy on firm borrowing decisions, and particularly so for small firms.

\section{2b. Additional Considerations}

There are several other avenues through which credit market imperfections may produce "excess volatility" of small firms. Each involves a fairly straightforward extension of the basic model. First, appending the framework to include variation in internal funds introduces an accelerator effect on

\footnotetext{
${ }^{13}$ See Farmer (1985), who also emphasizes how incentive problems in the credit market magnify the impact of interest rate shifts on output.
} 
input demand, as in Bernanke and Gertler (1989). ${ }^{14}$ This occurs because credit market frictions introduce a wedge between the cost of internal and external finance. In terms of Figure 1, a rise in internal funds shifts the ss curve outward, expanding input demand. This effect is stronger for small firms since, ceterus parabus, the required premium for external finance is proportionately higher for these kinds of firms.

Second, risk averse behavior by intermediaries is possible, which would impact largely on small firms. If an intermediary is unable to perfectly diversify, then its capital position may constrain the quantity of loans it supplies [see Bernanke and Gertler, (1987)]. This is true since the intermediary's depositors confront an incentive problem in lending to the intermediary akin to the one the intermediary faces in lending to its borrower. $^{15}$ The bank's capital position matters ultimately to its lending decisions because it affects the price it must pay depositors to attract funds. Fluctuations in bank capital therefore affect loan terms. The so-called "credit-crunch" of the current recession essentially works through this mechanism. The impact is greater on small firms since they are unable to substitute to the open market to obtain credit (since the monitoring and evaluation costs required to obtain "arms-length" credit are disproportionately large for these kinds of firms. $)^{16}$

\footnotetext{
${ }^{14}$ See Greenwald and Stiglitz (1988) and Calomiris and Hubbard (1990) for discussion of of a related mechanism.

${ }^{15}$ The inability to perfectly diversify idiosyncratic risk is critical to the argument why bank capital influences bank lending. Diamond (1984) shows, as a matter of theory, that depositors never face an incentive problem with a perfectly diversified intermediary. This is because any risk to depositors in this case is systemic, and is therefore observable.

${ }^{16}$ For related reasons, it seems that the recent liquidity effect models
} 


\section{Data Description}

Our empirical analysis investigates the cyclical sensitivity of small firms in comparison to large firms, and examines the differences in the co-movements of small and large firms with various indicators of monetary policy. We therefore require a data set that contains time series observations on firms by size class. To our knowledge, the only source for such data with any significant time series dimension is the Quarterly Financial Report for Manufacturing Corporations (QFR). Another advantage of the QFR is that it is comprehensive; this permits us to assess the overall significance of small firms in an important, cyclically sensitive sector.

The QFR reports quarterly net sales revenue for all manufacturing firms as well as net sales revenue disaggregated by eight different asset size classes. The asset size classes include all firms with total assets under $\$ 5$ million, all firms with assets between $\$ 5$ to $\$ 10$ million, $\$ 10$ to $\$ 25$ million, $\$ 25$ to $\$ 50$ million, $\$ 50$ to $\$ 100$ million, $\$ 100$ to $\$ 250$ million, $\$ 250$ to $\$ 1000$ million, and all firms with total assets greater than $\$ 1$ billion. The QFR therefore provides eight different time series of sales data. Each time series represents the total sales of all firms within one of the eight size categories. The data are available from 1958:Q4 to 1990:Q3. ${ }^{17}$

Although we have eight potential time series, we reduce the data to

which emphasize banks as a conduit of monetary policy (e.g., Fuerst (1990) and Eichenbaum and Christiano (1991)) would also predict a small firm effect.

${ }^{17}$ Changes in QFR data construction in 1974,1986, and 1989 lead to slight breaks in the level series. We corrected the level series by splicing the data, using the overlap period provided by QFR to create correction factors. 
just two series, one for small firms and one for large firms, by aggregating across size categories. We aggregate for two reasons. First, this greatly simplifies the empirical analysis and reduces the VAR systems to manageable levels. Second, and perhaps more importantly, by aggregating across time series, we can control for the bias that occurs in the data due to the asset cutoff levels being in nominal terms, as we will discuss shortly.

The cutoff level for small firms is $\$ 25$ million dollars in assets. We selected this level since previous panel data studies (e.g., Fazzari, Peterson, and Hubbard (1988), Gilchrist (1990)) suggest that firms that are liquidity constrained when making their investment decisions are concentrated in the vicinity of this size class and below. Table 1 reports the cumulative percentage of all manufacturing sales accounted for by firms with total assets less than the QFR cutoff. From column 3 of this table, one can see that by choosing a cutoff level of $\$ 25$ million, we maintain a substantial percentage of total manufacturing sales in our "small firms" category. At the start of the sample, small firms account for 38\% of total manufacturing sales. Because of the use of nominal categories, this figure drops to 197 by 1990 , still a substantial percentage of total manufacturing.

The other columns in this table highlight the effect of using nominal categories to classify rirms, since all categories of firms, except the largest, shrink over time as a percentage of total manufacturing sales. For example, the smallest category of firms (assets less than $\$ 5 \mathrm{~m}$ ) accounted for 267. of total manuracturing sales in 1960 , but only 127 by 1990 . In contrast, the largest category of firms accounted for $15 \%$ in 1960 and $56 \%$ in 1990. 
Table 1

Percentage or Manufacturing Sales in Cumulative Asset Size Classes:

$\begin{array}{llllllll}\text { Cumulative Asset size class: } \\ \text { Year } & \$ 5 \mathrm{~m} & \$ 10 \mathrm{~m} & \$ 25 \mathrm{~m} & \$ 50 \mathrm{~m} & \$ 100 \mathrm{~m} & \$ 250 & \$ 1 \mathrm{~b} \\ 1960 & 0.26 & 0.31 & 0.38 & 0.44 & 0.52 & 0.65 & 0.85 \\ 1970 & 0.21 & 0.24 & 0.29 & 0.34 & 0.39 & 0.49 & 0.70 \\ 1980 & 0.13 & 0.16 & 0.21 & 0.24 & 0.28 & 0.34 & 0.47 \\ 1990 & 0.12 & 0.15 & 0.19 & 0.22 & 0.26 & 0.32 & 0.44\end{array}$

We address the "nominal size category" problem in three ways. First, we work with growth rates of real sales across size categories, rather than levels, in order to mitigate the impact of the trend effect on levels induced by inflation. ${ }^{18}$ Second, we aggregate up to two size categories to control the direction of bias that remains in the growth rate series. This aggregation induces a bias that tends to understate the sensitivity of small firms relative to large firms to the effects of monetary policy and other macro shocks. For example, suppose there is a shift to expansionary monetary policy that eventually raises inflation: The bias works towards increasing the sensitivity of large firms, as the rate of rirms shifting into the higher asset category increases. By inducing a bias that dampens the relative reaction of small firms, we are more confident of the robustness of findings that imply small firms may be more sensitive to either cyclical or monetary shocks. Finally, in our empirical work, we

\footnotetext{
${ }^{18}$ We also remove seasonal effects in the sales growth rate series by regressing the data on seasonal dummies and using the residuals.
} 
allow inflation to enter as an independent variable in the equations for firm behavior, in order to capture any remaining effect on sales of category-shifting induced by inflation. ${ }^{19}$

We next report some descriptive statistics. We present two types: measures of relative volatility between the sales of large and small firms; and correlations between sales of large and small firms and GNP. We do not report average growth rates for the manufacturing sales data, since these measures are not comparable due to the trends in each series.

To compare the volatility of sales growth for small firms to the volatility of sales growth for large firms, we aggregate the sales data into two size categories and compute standard deviations for the growth rate in each category. We then construct a ratio of the standard deviation of the growth rate of small firms to the standard deviation of the growth rate of large firms. To account for the changing percentage of total manufacturing in any given size category, we look at different sub-periods in the data, computing 40 quarter standard deviations for each sub-period. To assess the sensitivity of this relative volatility measure to changes in the cutof used to classify firms into small and large categories, we vary the cutoff level used to divide the firms, starting with the lowest QFR cutoff and steadily increasing it. These results are reported in table 2.

\footnotetext{
${ }^{19}$ It is also noteworthy that the QFR keeps a firm in a size class for eight quarters before making any adjustment. This dampens considerably the number of firms which shift categories in the wake of a macro shock.
} 
Table 2

\section{Standard deviations of sales growth rates of firms below a cutoff relative to the standard deviation of firms above the cutoff}

$\begin{array}{cccccccc}\text { Year } & \$ 5 \mathrm{~m} & \$ 10 \mathrm{~m} & \$ 25 \mathrm{~m} & \$ 50 \mathrm{~m} & \$ 100 \mathrm{~m} & \$ 250 & \$ \underline{\underline{b}} \\ 1960-70 & 1.26 & 1.23 & 1.19 & 1.14 & 1.07 & 0.94 & 0.53 \\ 1970-80 & 1.24 & 1.25 & 1.25 & 1.20 & 1.14 & 1.06 & 0.96 \\ 1980-90 & 1.00 & 1.05 & 0.99 & 0.97 & 0.95 & 0.92 & 0.80\end{array}$

From table 2 it is clear that the smaller size categories exhibit as much if not more volatility than the larger size categories. For all cutoff levels below $\$ 250$ million, the standard deviation of sales growth for firms below the cutoff is much greater than the standard deviation of sales growth for firms above the cutoff for the time periods 1960-69, and 1970-79. Even in the 1980's, when the volatility of small firms appears to have decreased relative to large firms, this ratio is at least 0.99 for the bottom three cutoff levels. 20

While Table 2 concentrates on raw measures of sales volatility, Table 3 presents information about the cyclical volatility, measured by the co-movement with GNP. Specifically, it reports the correlation between real

${ }^{20}$ The volatility of sales growth appears to be bimodal across size categories however, since the largest size category also exhibits considerably more volatility than other categories. The last column of table 1 shows that the standard deviation of sales growth for firms with total assets greater than $\$ 1$ billion is considerably greater than the standard deviation of sales growth for firms with total assets less than $\$ 1$ billion. The variance of the largest category tends to decrease over time, relative to the rest of the sample, as one incorporates more of the less volatile intermediate size firms in this category. 
GNP growth and the growth rate in sales of small and large firms at various leads and lags. Overall, small firms are in the same league of cyclical volatility as large firms. Large firms have a slightly stronger contemporaneous correlation, .55 versus 44 . Small firms, though, appear to have a slightly stronger lag and lead relationship with GNP. This pattern is confirmed by the co-movement of the difference in the growth rates between small and large firms with GNP, reported in the third row.

Table 3

Cross Correlations for Growth Rates of Small and Large Firm Sales and GNP

$\begin{array}{lcccccccc}D 10 g(X)(t-s) & D \log (Y)(t) & \underline{s}=3 & \underline{s}=2 & \underline{s}=1 & \underline{s}=0 & \underline{s}=-1 & \underline{s}=-2 & \underline{s}=-3 \\ \text { Small Firms } & \text { GNP } & 0.01 & 0.11 & 0.24 & 0.44 & 0.37 & 0.26 & 0.07 \\ \text { Large Firms } & \text { GNP } & -0.08 & -0.06 & 0.16 & 0.55 & 0.26 & 0.06 & 0.16 \\ \text { Small-Large } & \text { GNP } & 0.10 & 0.18 & 0.12 & -0.06 & 0.15 & 0.21 & -0.07 \\ \text { Small Firms } & \text { Large Firms } & 0.01 & 0.02 & 0.26 & 0.47 & 0.12 & 0.18 & -0.15\end{array}$

In summary, the descriptive statistics imply that "small firms" account for a substantial fraction of total manufacturing sales; and that they are comparable to large firms in terms of overall variation and in terms of simple correlations with GNP.

\section{Empirical Results}

We now examine the macroeconomic performance of small versus large firms in the context of a set of VAR models. Each model includes both small and large firms, GNP, inflation and one or more indicators of monetary 
policy. Inflation is included in part to control for the possible bias owing to nominal size classifications (see the discussion in section 3). We estimate each model in two different forms: the first allows the growth rates of small firms and large firms to enter independently; the second restricts them to enter in difference form (i.e., the relevant firm variable is the difference in the sales growth rates of small and large firms). The former approach permits us to control in a flexible way for interactive effects between large and small firms. The advantage of the second approach is fewer parameters to estimate.

We use a number of different methods to assess the relative behavior of small and large firms. First, we present a set of exclusion restriction tests to determine the qualitative importance of GNP and the monetary variables for explaining the growth rates of small versus large firms. We further assess the quantitative magnitudes of these partial correlations by examining the size of the coefficients on various lags of the macroeconomic variables. Finally, we quantify the impact of an innovation in either GNP or in the stance of monetary policy on the overall dynamic behavior of small versus large firms, using impulse response functions. We follow two different approaches in the literature to identify exogenous shocks to the stance of monetary policy.

Because there is no universally accepted indicator of monetary policy, we consider a number of alternatives popular in the literature. The list includes: M2, the Federal Funds rate, the spread between the six month commercial paper and T-bill rates, the short term financing mix between bank loans and commercial paper, and the dummy variables for shifts to tight money that Romer and Romer (1989) constructed. M2 is picked because it is a 
traditional and widely-used measure of the stance of monetary policy. The limitation of M2 (and indeed of most of these indicators) is that a large component of its variation is likely endogenous. Although endogeneity amongst the macro variables still permits us to analyze the impact of shifting macroeconomic conditions on small versus large firm behavior, it constrains our ability to disentangle the impact of monetary versus real shocks.

The endogeneity problem leads us to two other indicators, the funds rate and the Romer dates. Bernanke and Blinder (1990) argue that it is reasonable to treat a component of the contemporaneous innovation in the funds rate as exogenous since the Federal Reserve sets this variable directly. Romer and Romer (1989) instead rely on the minutes of the Federal Reserve Open Market Committee to identify dates when the Federal Open Market Committee shifted the course of monetary policy to fight inflation. They argue that because these episodes reflect primarily responses to trend inflation, they may be treated as exogenous with respect to the recent behavior of output.

We consider the two other indicators, the spread and mix variables, because they may reflect credit market conditions not captured by the other measures. Both Romer and Romer (1989) and Bernanke (1990) present evidence suggesting that the spread is driven by monetary policy and, correspondingly, that it may be a good indicator of monetary tightness. Intuitively, tight money leads to relatively greater issuance of commercial paper and CDs (which are close substitutes for commercial paper), which historically placed upward pressure on the commercial paper rate relative to the T-bill rate. The attention the spread has received as a leading 
indicator also makes it a desirable candidate for study. Similar considerations lead us to the mix variable. Kashyap, Stein, and Wilcox (1991) present evidence suggesting that monetary policy affects the mix, which reflects the relative importance of bank loans versus commercial paper in short term finance. ${ }^{21}$ Tight money constrains the ability of banks to issue Ioans, this increases borrower's reliance on commercial paper. To the extent that bank loans and commercial paper are imperfect substitutes, the mix variable may be viewed as an indicator of credit tightness.

We begin by examining VAR systems which include the quantitative monetary variables: M2 growth, the Federal Funds rate, the risk spread, and the mix. Later we consider the Romer dummies. For each monetary variable we estimate two VAR models. The first includes four lags each of real sales growth of small firms, real sales growth of large firms, real GNP growth, inflation and of the particular monetary variable. ${ }^{22}$ The second differs by replacing the two firm sales growth variables with a single variable, the difference between the sales growth of small and large firms. ${ }^{23}$

Table 4 reports the exclusion test results for whether or not GNP

\footnotetext{
${ }^{2}$ Short term business bank loans actually appear to rise following tight money. The mix falls, therefore, because commercial paper rises faster. Evidence from the QFR, which we report in section 4, shows that while bank lending to large firms rises, bank lending to small firms actually contracts following tight money. Thus, the behavior of the mix may be at least partly explained by a compositional effect on small versus large firms.

${ }^{22}$ We also tried different lag lengths, none of which noticeably affected our results.

${ }^{23}$ All equations are estimated over the period 1960:Q2 to 1990:Q3, except for the regression that includes the mix variable. Because the commercial paper market did not develop unit! the mid-sixties, regressions using the mix are estimated over the period 1965:Q1 to 1990:Q3.
} 
growth and various monetary variables provide additional explanatory power for the sales growth rates of small and large firms. Figure 5 plots the individual coefficients on lags 1 to 4 of each macro variable, as well as the sum of the coefficients and $95 \%$ confidence intervals, for the regressions with small and large firms as the dependent variables. Figure 6 does the same for the regressions with the difference between small and large firm growth rates as the dependent variable. These figures also report the $\mathrm{R}^{2}$ and the standard error of the regression that resulted from these regressions. The exclusion tests we report for GNP growth are obtained from the VAR system that includes the Federal Funds rate as the monetary variable. ${ }^{24}$ For the exclusion tests of other monetary variables, besides the Funds rate, we use the same regressions, replacing the Funds rate with the monetary variable of interest.

\footnotetext{
${ }^{24}$ We focus on the VAR system with the Funds rate, since it is the monetary variable likely to be least endogenous with respect to contemporaneous movements in GNP.
} 
Table 4

Exclusion Tests for GNP and Monetary Variables ${ }^{25}$

$\chi^{2}$ statistic, p-value in parentheses

GNP Growth M2 Growth Funds Rate Risk Spread Mix Growth

$\begin{array}{lccccc}\text { Small Firms } & 11.31 & 12.24 & 12.31 & 5.22 & 14.23 \\ & (0.02) & (0.02) & (0.02) & (0.26) & (0.01) \\ \text { Large Firms } & 6.22 & 6.12 & 17.58 & 14.18 & 2.35 \\ & (0.18) & (0.19) & (0.00) & (0.01) & (0.67) \\ \text { Small-Large } & 13.12 & 13.37 & 11.24 & 3.62 & 13.93 \\ & (0.01) & (0.01) & (0.02) & (0.46) & (0.01)\end{array}$

The first column of Table 4 indicates that GNP is a qualitatively more important predictor for small firm behavior. One rejects the hypothesis that lags of real GNP growth do not explain the sales growth of small firms. But one cannot reject it for large firms. Figures 5 and 6 suggest that lagged GNP is also a quantitatively more important predictor of small firm behavior. In Figure 5, all of the coefficients on lagged GNP are higher for small firms than large firms. Figure 6 confirms this pattern, using the difference in sales growth as the dependent variable; the coefficients on lags 2 and 4 as well as the sum are significantly positive. We interpret these results as being consistent with the idea that credit market imperfections make small firms more sensitive to aggregate demand and

\footnotetext{
${ }^{25}$ The regressions for the first two rows include four lags each of the real growth of small firms, the real sales growth of large firms, real GNP growth, and the monetary variable listed on top of the column. For the first column, which lists GNP at the top, the funds rate is the monetary variable. The regressions for the third row replace the two sales growth variables with the difference between the sales growth of small and large firms.
} 
technology shocks. ${ }^{26}$

The monetary variables also differ in predictive power for small and large firms, mainly in ways consistent with our theory. The results for M2 are quite striking. One overwhelmingly rejects the hypothesis that all the coefficients on lags of $M 2$ growth are equal to zero for small firms.

Conversely, M2 growth does not appear to help explain the growth rates of large firms, since one cannot reject the hypothesis that these coefficients are zero. M2 is also a quantitatively more important predictor of small firm behavior; and it is important to recognize that this holds true after controlling for the impact of GNP, inflation, and possible interactive effects between large and small firms. The coefficient patterns in Figures 5 and 6 indicate a stronger positive relation for small firms with lagged movements in M2, than for large firms.

The Federal Funds rate is a significant predictor of both large and small firm behavior, once again after controlling for GNP, inflation and interactive effects between large and small firms. One interesting difference is that small firms appear to react quicker to movements in the Funds rate. The coefficient patterns in both Figures 5 and 6 suggest that small firm sales growth decline one quarter after a rise in the Funds rate,

\footnotetext{
${ }^{26}$ If one uses M2 growth instead of the Funds Rate, one cannot reject the exclusion restriction on GNP for either large or small firms, however the coefficients on GNP still tend to be larger, with the difference being statistically significant for two of the four lags. If one uses the risk spread instead of the Funds rate, GNP appears to matter for large firms but not small firms. All the coefficients on GNP are negative for large firms however, and either significantly positive or close to zero for small firms. Further, the pattern on the GNP coefficients of small firms relative to large firms is quite similar across the different specifications, with the coefficients on the 1st, 2nd and 4th lag tending to be significantly greater for small firms than large firms, and the third lag being equal.
} 
everything else equal. ${ }^{27}$ The decline is both in absolute terms and relative to the sales growth of large firms. It takes large firms two quarters to decline after a rise in the Funds rate, again everything else equal.

Moreover, as we discuss shortly, the predictive power of the Funds rate for large firms appears to be proxying for the predictive power of the risk spread.

The risk spread produces a pattern nearly the opposite of M2. It is a significant predictor for large firms but not for small firms. At the same time, though, the coefficient patterns do not look much different between large and small firms. ${ }^{28}$ It is also interesting that, when both monetary variables are included, the risk spread eliminates the explanatory power of the Funds Rate for large firms but not for small firms. ${ }^{29}$ of all the

${ }^{27}$ One possible explanation for the quick decline in small firm sales in the wake of a rise in the Funds rate is that small firms may have to sharply contract the offering of trade credit finance their sales. In periods of tight money, banks may be willing to supply loans to $f$ inance inventories (since these loans are collateralized by the inventories.) They may be less willing to finance firms' of ferings of trade credit since the collateral value of these kinds of loans is highly uncertain. We are currently pursuing evidence on these possibility. See Ramey (1991) for a discussion of the widespread use of trade credit in business sales.

28 Because the Fed did not start targeting the Funds rate until the mid sixties, we reran these regressions using the sample period 1965:Q1-1990:Q3. This did not change our results.

We also considered dropping the last ten years of the sample since Bernanke argues that the rate spread is a less effective explanator in the 80 's than earlier. Not surprisingly, this weakened the impact of monetary policy across both small and large firms. Although M2 was no longer significant, the p-value was much higher for the difference in growth rates (0.15) and for the growth rate of small firms (0.27) than for the growth rate of large firms large firms (0.57). The Funds rate followed a similar pattern, with p-values of $0.05,0.11$, and 0.33 for the small and large firms respectively. Similarly, the $p$-values for the risk spread were $0.6,0.65$ and 0.58; thus once one drops the 80 's the spread does not appear to matter more for large firms.

${ }^{29}$ Conversely, when included jointly, both the Funds rate and $\mathrm{M} 2$ are 
monetary variables, the behavior of large firms is most closely tied to the risk spread.

The mix variable produces results quite similar to the impact of $\mathrm{M} 2 .^{30}$ It is a much better predictor for small firms than for large firms. The exclusion tests indicate a significance level of less than 17 for small firms, as compared to better than $67 \%$ for large firms. It is also true that the first three coefficients on the mix are positive for small firms, as is the sum. This is the pattern one would expect, given that a fall in the mix reflects credit tightening. Conversely, the coefficients on the mix for large firms are not significantly different from zero at lags 1,2 and 4 , as is the sum. Overall, the mix has very little independent explanatory power for large firms.

It is worth considering why small firms have a closer statistical relationship with $M 2$ and the mix, but large firms are in closer sync with the risk spread. Because each of these monetary variables has a significant endogenous component, any structural explanations must proceed with caution. It is interesting, though, that $M 2$ and the mix are closely tied to movements in bank credit, the primary source of external finance for small firms, while the spread is most directly a barometer of conditions in the commercial paper market, where large firms participate. Part of the story, therefore, may be that $M 2$ and the mix better proxy credit conditions for

significant predictors of small firm behavior. Thus, it is probably safe to say that the Funds rate and $M 2$ are jointly informative about small firms, while it is the risk spread that is informative about large firms.

${ }^{30}$ The mix variable we use is the growth rate of bank loans minus the growth rate of commercial paper. We differ slightly with Kashyap, Stein and Wilcox (1991) because we are studying growth rates rather than leveis. 
small firms, while the spread better captures conditions for large firms. ${ }^{31}$ We will present some evidence shortly indicating that the current recession appears to conform to this pattern.

We now compare the quantitative response of small and large firms to innovations in monetary policy and GNP. As mentioned earlier, we use two different methods existing in the literature to identify exogenous movements in monetary policy. We first consider a VAR framework with the Funds rate as the monetary variable, and treat as exogenous the component of the innovation in the Funds rate that is uncorrelated with the innovations of the other variables in the system, following Bernanke and Blinder (1990). We subsequently use dummy variables to proxy periods of exogenous shifts to tight money, following Romer and Romer (1990). For parsimony, we present results for systems where the difference between small and large firm growth rates is the exclusive firm variable. Results for the systems in which small and large firms enter independently do not differ appreciably.

Figure 7 plots the impact of a one standard deviation increase in the Funds rate on the difference between small and large firm growth rates. ${ }^{32}$ It also plots the response of GNP for comparison purposes. To obtain the impulse response functions, we orthogonalized the shocks using the following

\footnotetext{
${ }^{31}$ As Bernanke (1990) observes, the predictive of the spread has declined in recent years, and the spread failed to widen significantly prior to the current recession. Many economists, however, associate the current recession with a credit crunch on small firms. This observation and the fact the spread hasn't widened is compatible with our evidence, which suggest that small firm behavior is not highly correlated with the spread.

${ }^{32}$ The standard error bands are computed using 1000 draws from the Normal-inverse Wishart posterior distribution of the coefficient vector.
} 
ordering: GNP, inflation, small minus large firms, the Funds rate. ${ }^{33}$ The Funds rate is placed last to allow for the possibility that the Federal Reserve may set this variable based on contemporaneous information about any of the other variables. Also implicit in this formulation is the assumption that it takes at least one period for the Funds rate to affect the other variables. The overall structure closely parallels Bernanke and Blinder (1990).

Figure 7 suggests that a shock to the Funds rate has a greater cumulative impact on small firms than on large. When gauged against the overall impact on GNP, the effect appears nontrivial. For more than two years following a rise in the Funds rate the expected gap between small and large growth is more negative than the expected absolute decline in GNP growth. It also appears that small firms react more quickly; nearly half the overall decline relative to large firms occurs in the first two quarters.

A one standard deviation increase in GNP growth also has a relatively greater impact on small firms, though the difference with large firms is smaller than in the case of the Funds rate shock. This difference is also not significantly different from zero due in large part to noise in the contemporaneous relationship with GNP, as the width of the standard error bands at period zero indicate. Indeed, as Table 4 and Figures 5 and 6 show, lagged GNP has a significantly stronger impact on small firms. This is reflected in Figure 8 by the fact that, after period zero, the mean growth

${ }^{33}$ The impulse response functions are insensitive to the ordering the Funds rate third rather than fourth. Also, if the three macro variables are placed first, the precise ordering of the three makes no significant difference. 
in the difference rises on net for four quarters and the standard error bands do not widen appreciably. Simultaneity between the manufacturing sector and GNP could explain the absence of a small firm effect in the contemporaneous correlation (i.e., at period zero). The weaker results for GNP in comparison with the Funds rate experiment may also suggest that monetary policy is an important dimension of the differential behavior of small firms.

To check the robustness of our results on the impact of a monetary shock, we repeat the experiment, this time using the Romer dummies as the indicators of the stance of monetary policy. We augment the Romer dates by including the credit crunch of 1966:Q2 as another episode during which monetary policy shifted exogenously. Kashyap, Wilcox, and Stein (1990) discuss evidence from a rereading of the FOMC minutes that suggests this episode may fit the criteria used by the Romers. ${ }^{34}$

We follow Romer and Romer by including three years of lags (twelve since we use quarterly data) of the dummy variables in our VAR system. We estimate two different models. The first includes GNP, inflation, the difference between small and large firms, and the Romer dummies. The second adds the Funds rate to the system. The purpose is to address the problem that the Romer dummy does not measure the intensity of the policy shift. A crude way of capturing the overall degree of monetary tightness is to include a quantitative measure of the stance of monetary policy along with the qualitative dummies.

${ }^{34}$ Excluding the credit crunch does not significantly alter the results. 
Figures 9 thorugh 12 plot the response of the difference between sales growth of small and large firms to a Romer episode, along with the coefficients on the Romer dummies. The impact of a Romer episode on small firms relative to large is clearly negative and prolonged. This is true whether or not the Funds rate is included. All the Romer dummy coefficients are negative, with five out of twelve being significantly different from zero. The impact is substantial. ${ }^{35}$ For two and a half years following a Romer shock small firms sales drop more than four percent per year faster than large firm sales. This exceeds the absolute drop in the GNP growth rate. Also, for most of the period, a two-standard deviation error band for small minus large firm sales lies below zero.

The overall sharp decline in small firms relative to large is in part due to the direct impact of the Funds rate and in part to the indirect effect of the decline in GNP. Either channel is compatible with our theory. Credit market imperfections induce a magnified response of small firms to aggregate demand and technology shocks, as well as to monetary shocks. As we argue later, alternative theories do not easily explain our variety of facts.

To further explore the role of financial factors, we also examine the behavior of bank lending for each class of firms following tight money. ${ }^{36}$ We

${ }^{35}$ The Romer shock is not exactiy comparable to the Funds rate shock, since in the latter case, the dynamics permit the Funds rate to revert back to trend. Another possible difference owes to the fact that asymmetries may be present, since the credit frictions are more likley to bind in bad times than in good times. Since the Romer dates include only tight money periods, they may capture an asymmetric response.

36 The QFR provides balance sheet data on bank lending for the same 
add the real growth rates of bank lending to large and small firms to the VAR system that includes the Funds rate (but not the Romer dummies). Figure 13 reports the cumulative response of each of these variables to a one standard deviation rise in the Funds rate. Clearly, lending to small firms declines, while it rises for large firms. In Figure 14 we perform a similar experiment, this time using the ratio of the growth of bank loans to the growth of sales for each class of firms. The cumulative impact on this ratio for small firms is never significantly different from zero. On the other hand, this ratio for large firms rises sharply for the first year after the Funds rate increase. Both the results in Figures 13 and 14 are consistent with the possibility that monetary policy has a stronger direct impact on small firms; and, relatedly, that small firms are less able than large firms to borrow to smooth the impact of declining sales.

An informal graphical description of the sales data provides further insight into our results. Figure 15 plots the sales growth of small and large firms along with a smoothed version of these growth rates. The smoothed data is the product of a non-parametric filter designed to pick up broad movements. ${ }^{37}$ In particular, the filter dampens the impact of infrequent large movements in the data. ${ }^{38}$ The smoothed data is thus able to characterize the differential behavior between, large and small firm growth

size categories as sales. We adjusted for level changes due to reclassification using the same method we used when correcting sales.

${ }^{37}$ We smoothed the data using an Splus program that robustly smooths a time series by means of running medians.

${ }^{38}$ The lines reflecting the smoothed data should not be interpreted as low frequency trends. In contrast to the Hodrick-Prescott filter, this filter Hodrick-Prescott filter, this filter does not decompose the the data into a trend of lower frequency than the business cycle and a cyclical component. 
rates in sharp relief. The pictures in Figure 15 are in harmony with our formal regression results. Small firms appear to exhibit much steeper and larger declines around both recessions and Romer episodes. The only exception is the 1974 Romer date, which coincided with an oil shock. Indeed it is interesting to note that small firms react more strongly than large firms, not only during major monetary contractions, such as 1979 , but also during the more moderate contractions such as 1968 and 1978.

Finally, it is interesting to extend the analysis to the current recession. Figure 16 plots the growth rates of small and large firms from 1988:Q1 through 1991:Q1. A smoothed version of the data is presented in the panel below. ${ }^{39}$ For six of the seven quarters in the period leading into the recession, 1989:Q2 to $1990: \mathrm{Q}$, the growth rate of small firms is substantially below the growth rate of large firms. There is some evidence to suggest that in the latter half of this period, 1990:Q2 to 1990:Q4, the relative slow growth of small firms may have been due to a credit crunch, defined as a disruption of credit owing to poor health of the banking system. This interpretation is based on the behavior of the financial aggregates over this period, as plotted in Figure 17.

Gradual monetary tightening appears to have occurred over the first half of the overall period, 1988:Q1 to 1989:Q2. This is reflected by the steady decline in $M 2$ growth, the steady rise in the funds rate, the mild rise in the risk-spread, and the decline in the mix variable. This monetary contraction appears to produce a decline in both small and large firm growth

\footnotetext{
${ }^{39}$ The smoothed data is obtained from applying the Splus program to the entire sample period (1959:Q1 - 1991:Q1), and not only the recent quarters.
} 
rates throughout 1989 , with the small firm growth rate falling faster. All the monetary aggregates reverse course in 1989:Q3, reflecting a beginning of monetary ease. Symptoms of a crunch begin in 1990:Q1. While the Funds rate and the risk-spread continue downward, (possibly reflecting continued monetary ease), $M 2$ growth begins to decline and the mix variable falls sharply. One would expect problems in banking to reduce M2 growth and growth of the mix. They would also tend to place downward pressure on the spread, owing to a decline in the issuance of $\mathrm{CDs} .{ }^{40}$ The credit crunch interpretation is butressed by the fact that for the three quarters subsequent to 1990:Q1, small firms grow at a rate considerably below large firms.

It is worth adding that the overall picture is consistent with our general finding that small firms have tended to move positively with both $M 2$ and the mix (after controlling for GNP, inflation, and large firms), while large firms have tended to move inversely with the risk spread (after controlling for GNP, inflation and small firms). It is also interesting to observe how well small firm behavior tracks the mix, with a one period lag. Indeed, the one quarter in the interval 1989:Q2 - 1990:Q4 where small firms grew faster than large firms was preceeded by rapid growth of the mix. This one period lag also appears in the formal econometric work (see Figures 5

\footnotetext{
${ }^{40}$ One difference of the current recession from the previous ones is that the growth rate of managed liabilities of financial intermediaries (large CDs and Eurodollar deposits) declined in the period preceding the downturn. In the past, managed liabilities have grown sharply as financial institutions have tried to offset the effects of tight money. Since CDs are close substitutes for commercial paper, the contraction in the supply of managed liabilities may be part of the explanation for why the risk spread did not rise appreciably this time around. See Bernanke (1990) for a general discussion.
} 
and 6.)

\section{Concluding Remarks}

Macroeconomics has traditionally focused on the behavior of large firms. In our view, small firms deserve attention as well. Because they are more likely to face credit market imperfections, small firms are particularly sensitive to macroeconomic disturbances, including shifts in monetary policy. The evidence in this paper is supportive of this view. We show, using several methodologies, that monetary policy has a relatively larger impact on small firms. Perhaps the most striking statistic is that for a period of two years and a half following a Romer episode of tight money, the average annual growth rate of small manufacturing firms is more than four percentage points below the average annual growth rate of large manufacturing firms.

Our coefficient estimates suggest that the differential response of small firms to tight money is due both to the direct impact of monetary policy and to the indirect impact working through the overall decline in economic activity (small firms are more sensitive to movements in GNP). Either channel is consistent with our emphasis on credit market imperfections, since the model we developed predicts that small firms should be excessively sensitive not only to to interest rates, but also to demand or technology shifts. The fact that bank loans to small firms decline following a rise in the Funds rate, while they instead rise for large firms, is further evidence compatible with our emphasis on financial factors.

Could a frictionless framework explain our results? One possibility is that small firms are concentrated in industries that are both 
highly-interest sensitive and cyclical, implying that we are merely capturing industry effects. The data required to fully resolve this issue is currently incomplete. The available data, however, suggests that a simple industry effects story is unlikely; it indicates no particular pattern in the distribution of small firms between cyclical versus non-cyclical manufacturing industries. A second possibility is that technological factors make small firms more volatile, perhaps because they are generally less capital intensive (e.g., Mills and Schumann (1985)). ${ }^{41}$ However, pure technological stories could easily lead to the opposite predictions. One could argue, for example, that large firms should have greater flexibility in responding to shocks because they are likely to have greater excess capacity. And being more capital intensive also should, everything else equal, make large firms more sensitive to interest rate shifts. Explaining the differential response of bank lending for small and large firms to Funds rate shocks also appears problematic in a perfect markets setting. Nonetheless, we agree that discriminating between these various hypotheses is clearly an item deserving of further research.

A related objective, which we are currently pursuing, is expanding the data set beyond the manufacturing sector. Because the percentage of small firms in the manufacturing sector is well below the percentage for the economy as a whole (see Gertler and Hubbard (1989)), it is quite possible

\footnotetext{
${ }^{41}$ Our results cannot be explained by the fact that small firms are typically less diversified. This kind of story explains why small firms may have a lot of idiosyncratic volatility, but is does not explain systematic volatility (i.e., co-movement with the cycle). Nor, in the absence of informational frictions, can it explain a greater sensitivity to monetary policy.
} 
that our analysis has understated the overall macroeconomic relevance of small firms.

Finally worth noting are the results that both $M 2$ and the mix between commercial paper and bank loan financing contain considerably more predictive power for small firms than for large firms (while at the same time, the commercial paper/ T-bill spread is a better predictor for large firms). Both $M 2$ and the mix variable are financial aggregates that are tied closely to the performance of banking. And small firms have traditionally been heavily dependent on bank financing. These kinds of financial/real regularities should not occur in a Miller/Modigliani world. Our results, therefore, are sympathetic to theories emphasizing the behavior of banks (and, relatediy, the behavior of small firms and other "small" borrowers) both in the monetary transmission mechanism and in the business cycle. 


\section{Appendix: The Case of Rationing}

The impact of a rise in the promised payment on the expected return to the firm's debt is given by $(1-p)-\gamma / 2 \theta x$ ithe denominator in $\partial p / \partial x--$ see equation (6)1. In the text we implicitly assumed that this value is positive, which guarantees that the supply curve in Figure 1 is always upward sloping. This hypothesis is quite reasonable under plausible outcomes for the bankruptcy probability $p$ and for the ratio of the default cost to output. It is conceivable that this condition is violated for very small firms, in particular, for firms where $\theta$ is quite small relative to $\gamma$. For these kinds of firms, the supply curve bends backwards. The optimum is accordingly the maximum feasible value of $\mathbf{x}$. Even though these firms are "rationed", however, shifts in $\theta$ and $r$ still have a magnified impact. In analogy to Williamson (1987), the solution under rationing is found as follows: Conditional on $x$, the choice of $p$ which yields the maximum expected return to the intermediary is given by the condition that the net marginal rise in the intermediary's expected payoff equal zero:

$$
(1-p)-\gamma / 2 \theta x=0
$$

This condition and equation (3), which requires that the intermediary receive a competitive return, then jointly determine $x$ and $p$. Further, by incorporating (7), (3) may be simplified to

$$
p^{2}=(1 / 2)(r / \theta) x
$$

Figure 4 illustrates the equilibrium for the rationing case. The supply curve bends backward before it intersects the demand curve. The value of $\mathbf{x}$ at which it bends backward is the optimum. Equations (A1) and (A2) define this 
value.

Relative to the benchmark of perfect markets, $\mathrm{x}$ is more responsive to shifts in $\theta$ and $r$. A percentage rise in $r$ induces more than a percentage decline in $\mathbf{x}$. (Recall that this elasticity is -1 under perfect markets.) The argument may be seen in two steps. Because in this case raising the promised payment reduces the intermediary's expected return, the rise in $r$ requires a fall in $x$ to reduce the size of the loan. The fall in $x$, however, increases the average ex post bankruptcy cost, $\gamma / \theta x$, forcing a further reduction in $\mathbf{x}$, in order to bring down the default probability $p$. In terms of Figure 2, the rise in $r$ rotates the supply curve upward, shifting the optimum inward. For analogous reasoning, a shift in $\theta$ also has a magnified impact on $\mathbf{x}$. 


\section{References}

Bernanke, Ben, 1990, "On the Predictive Power of Interest Rates and Interest Rate Spreads," NBER Working Paper No. 3486.

Bernanke, Ben and Alan S. Blinder, 1988, "Is It Money or Credit, or Both, or Neither?," American Economic Review, May 1988, 435-439.

Bernanke, Ben and Alan S. Blinder, 1990, "The Federal Funds Rate and the Transmission of Monetary Policy," NBER Working Paper No. 3487.

Bernanke, Ben and Mark Gertler, 1987, "Banking and Macroeconomic Activity" in New Approaches to Monetary Economics, edited by William Barnett and Kenneth Singleton, (New York, Cambridge University Press).

Bernanke, Ben and Mark Gertier, 1989, "Agency Costs, Net Worth and Business Fluctuations," American Economic Review, March, 14-31.

Blinder, Alan S., and Joseph Stiglitz, 1983, "Money, Credit Constraints and Econornic Activity," American Economic Review, 297-302.

Calomiris, Charles, and R. Glenn Hubbard, 1990, "Firm Heterogenity, Internal Finance and Credit Rationing," Economic Journal 100, March, 90-104.

Diamond, Douglas, 1984, "Financial Intermediation and Delegated Monitoring," Review of Economic Studies, July, 393-414.

Eckstein, Otto, and Alan Sinai, 1986, "The Mechanisms of the Business Cycle in the Postwar Data," in The American Business Cycle: Continuity and Change,

Eichenbaum, Martin S. and Lawrence Christiano, 1991, "Liquidity Effects, Monetary Policy, and the Business Cycle," mimeo.

Evans, David, and Boyan Jovanovic, 1989, "An Estimated Model of Entrepreneurial Choice under Liquidity Constraints," Journal of Political Economy 94, August, 808-827.

Farmer, Roger, 1985, "Implicit Contracts with Asymmetric Information and Bankruptcy," Review of Economic Studies, July, 427-442.

Fazzari, Stephen, R. Glenn Hubbard, and Bruce Peterson, "Financing, Constraints and Corporate Investment," 1988, Brookings Papers on Economic Activity, no.1, 141-195.

Fuerst, Timothy, 1990, "Liquidity, Loanable Funds, and Real Activity," mimeo.

Gale, Douglas and Martin Hellwig, 1985, "Incentive-Compatible Debt Contracts 1: The One-Period Problem," Review of Economic Studies, October, 647-64. 
Gertler, Mark, forthcoming, "Financial Capacity and Output Fluctuations in An Economy with Multiperiod Financial Relationships," Review of Economic Studies.

Gertler, Mark and R. Glenn Hubbard, 1989, "Financial Factors in Business Fluctuations," In Financial Market Volatilityi Causes, Consequences, and Policy Recommendations, Federal Reserve Bank of Kansas City.

Gilchrist, Simon, 1990, "An Empirical Analysis of Corporate Investment and Financing Hierarchies using Firm Level Pane! Data," mimeo.

Gilchrist, Simon, 1990, Iwo Essays on Investment and Credit Market Imperfections, University of Wisconsin Phd. thesis.

Greenwald, Bruce, and Joseph Stiglitz, 1988, "Information, Finance Constraints and Economic Activity," in Finance Constraints, Expectations and Economic Activity, edited by Meir Kohn and S.C. Tsiang, (Oxford, Oxford University Press), 14I-165.

Kashyap, Anil, David Wilcox, and Jeremy Stein, 1991, "The Monetary Transmission Mechanism: Evidence From the Composition of External FInance", FEDS Working Paper No. 151.

Mills, David, and Laurence Schumann, 1985, "Industry Structure with Fluctuating Demand," American Economic Review, September, 758-767.

Ramey, Valerie, 1991, "The Source of Fluctuations in Money: Evidence in From Trade Credit," NBER Working Paper No. 3756.

Romer, Christina D., and David H. Romer, 1989, "Does Monetary Policy Matter? A New Test in the Spirit of Friedman and Schwartz," NBER Macroeconomics Annual 4, 121-170.

Romer, Christina D., and David H. Romer, 1990, "New Evidence on the Monetary Transmission Mechanism," Brookings Papers on Economic Activity 1.

Sims, Christopher, 1980, "Comparison of Interwar and Postwar Business Cycles: Monetarism Reconsidered," American Economic Review 70, May, 250-57.

Townsend, Robert, 1979, "Optimal Contracts and Competitive Markets with Costly State Verification," Sournal of Economic Theory 21, October, 265-293.

Williamson, Stephen, D., 1987a, "Financial Intermediation, Business Failures, and Real Business Cycles," Journal of Political Economy 95, December. $1196-1216$.

Williamson, Stephen, D., 1987b, "Costly Monitoring, Optimal Contracts, and Equilibrium Credit Rationing," Quarterly Journal of Economics 102 , February, 135-45. 
Figure 1

Input Choice in the Basic Case

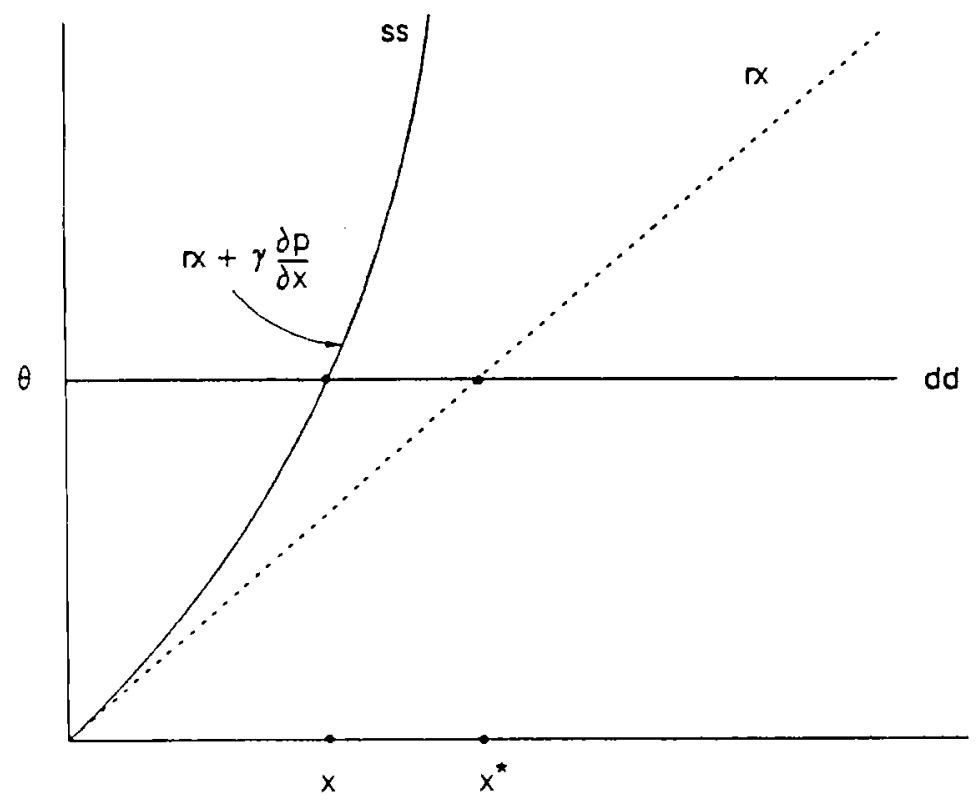


Figure 2

Impact of a Rise in $\theta$ in the Basic Case

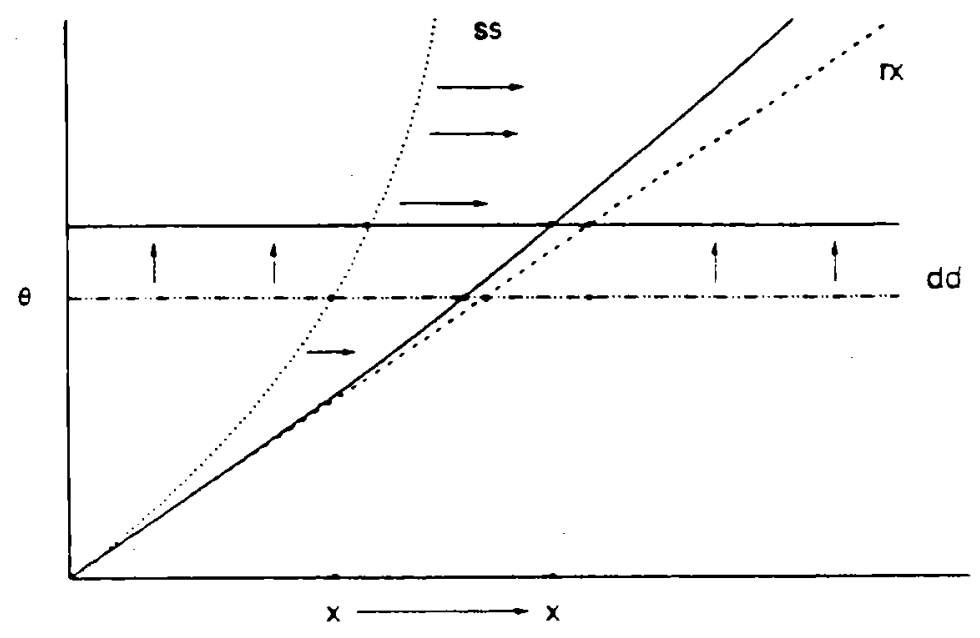

Figure 3

Impact of a Rise in $r$ in the Basic Case

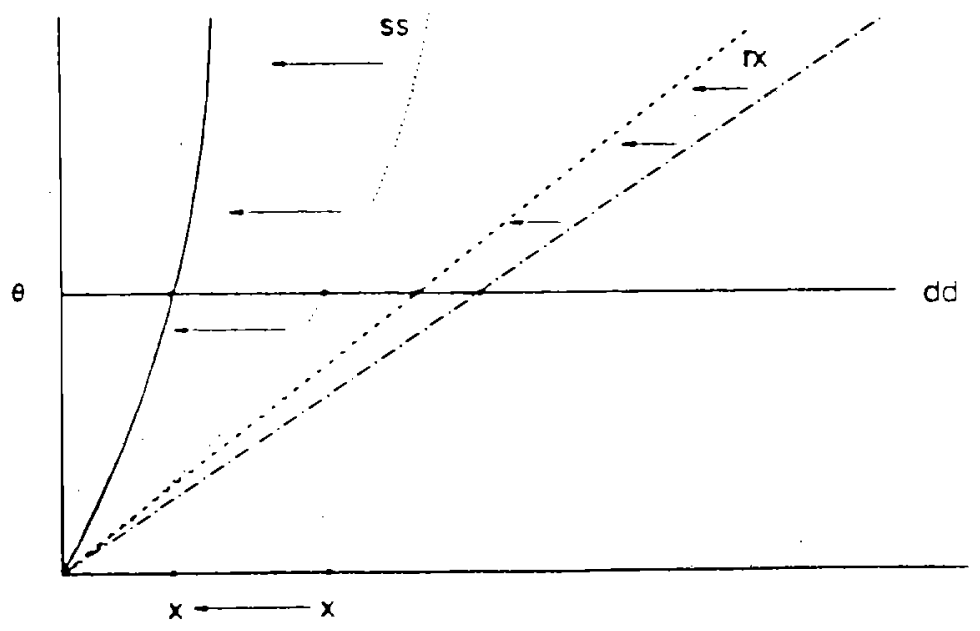


Figure 4

Input Choice in the Rationing Case

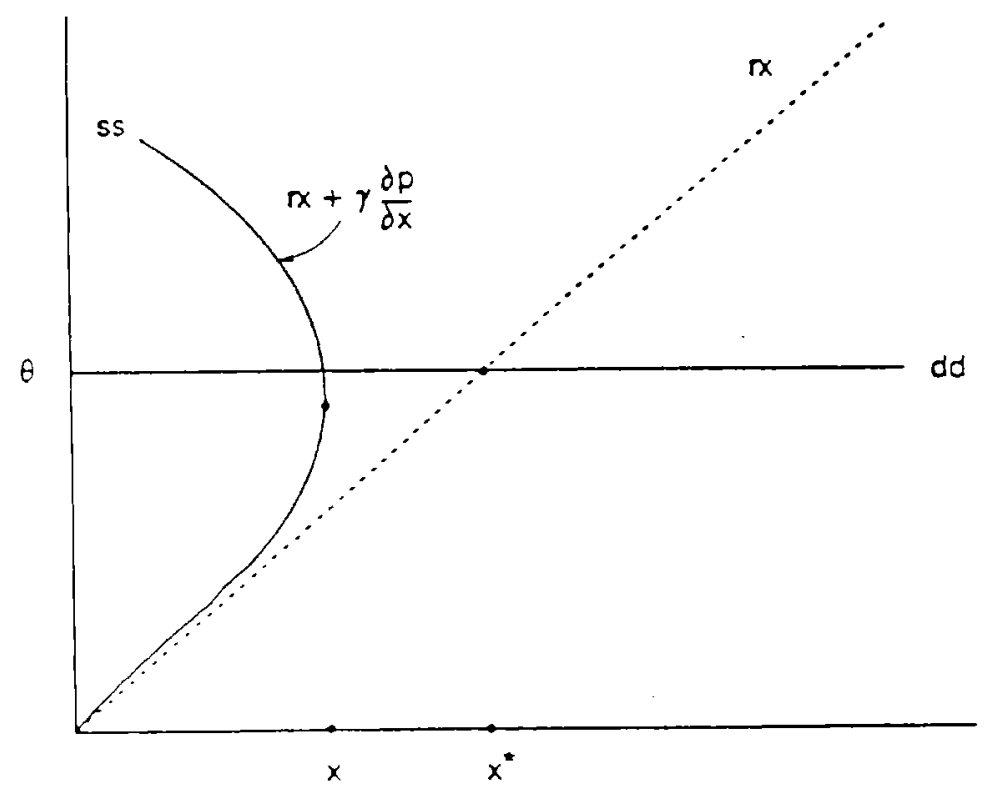


Figure 5

95\% Contidence Intervals for M2 Growth Coefficients

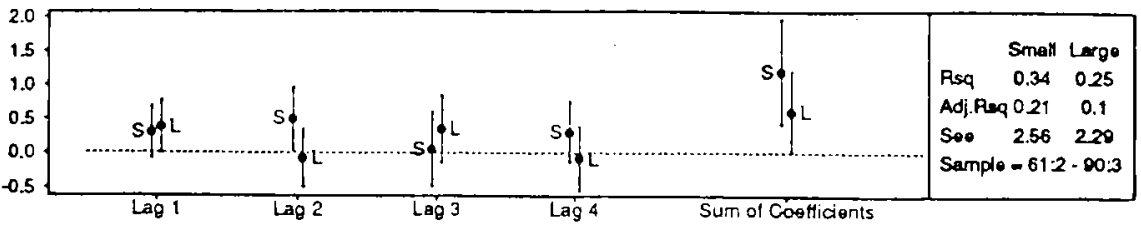

95\% Confidence Intervals for Federal Funds Rate Coelficients

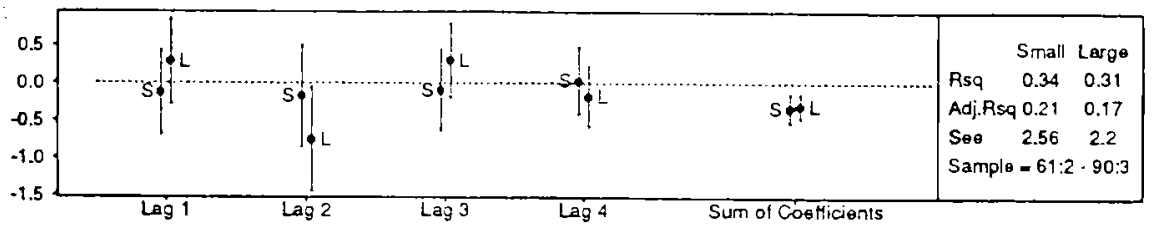

95\% Confidence Intervals for Risk Spread Coefficients

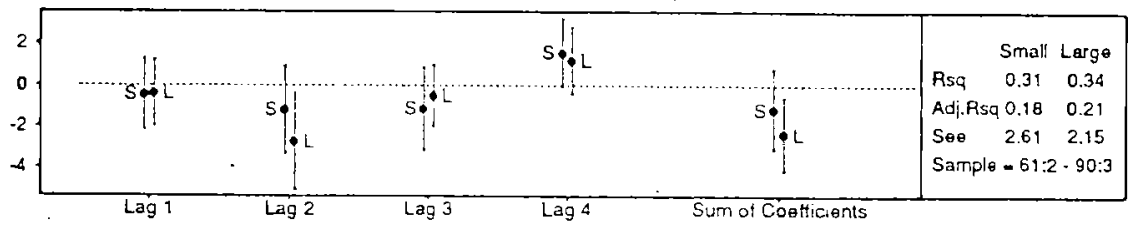

95\% Confidence Intervals for Mix Growh Coefficients

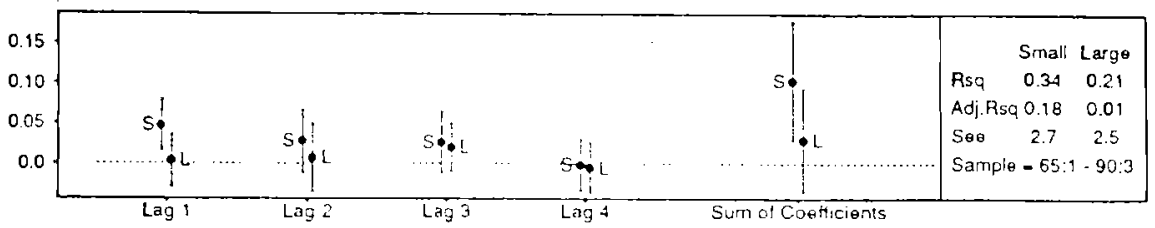

95\% Confidence Intervals tor GNF Growth Coefticients. Regression with FFR

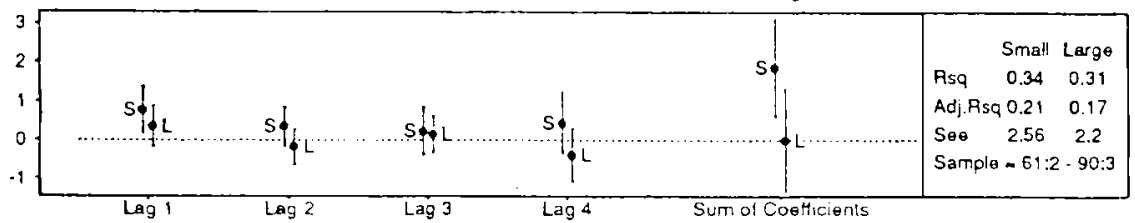




\section{Figure 6}

$95 \%$ Confidence Intervals for M2 Growth Coefficients

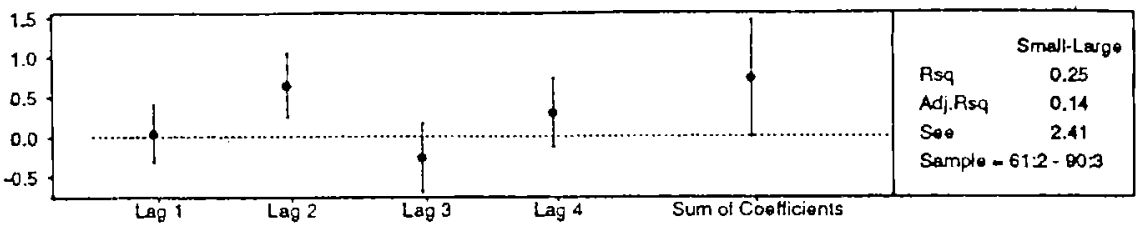

95\% Confidence Intervals for Federal Funds Rate Coefticients

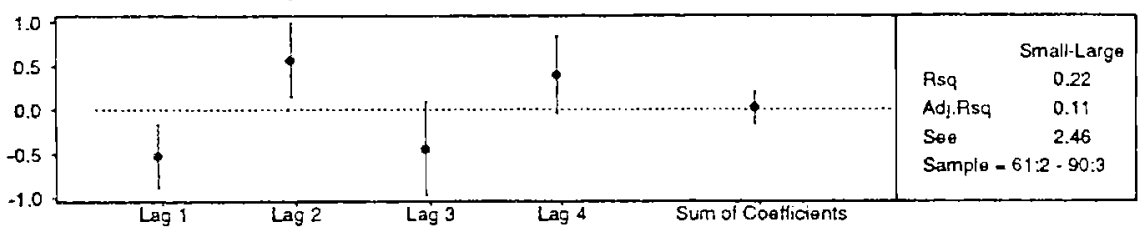

$95 \%$ Confidence Intervals for Risk Spread Coetticients

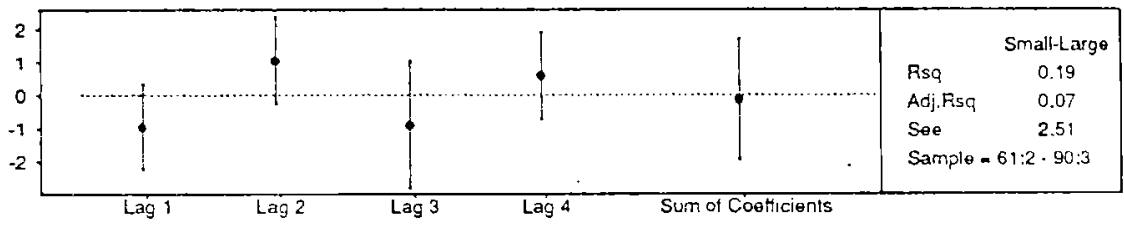

$95 \%$ Confidence Inlervals for Mix Growth Coefficients

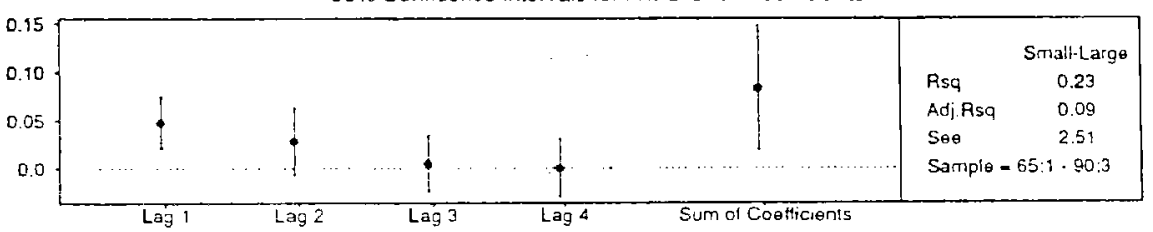

95\% Contidence Intervals 10 GNP Growth Coefficients, Regression with FFR

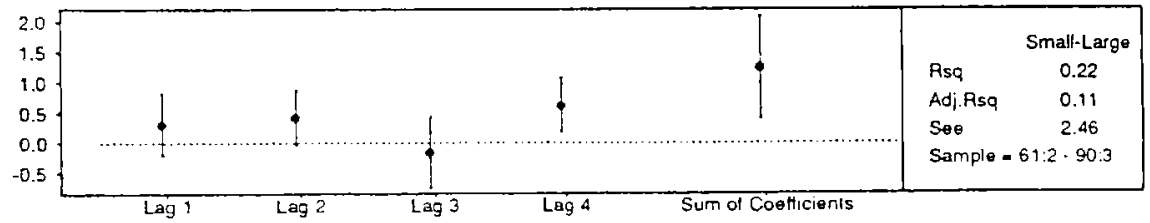


Figure 7

Impulse Response of the Difference in Sales Growth to an Increase in the Federal Funds Rate

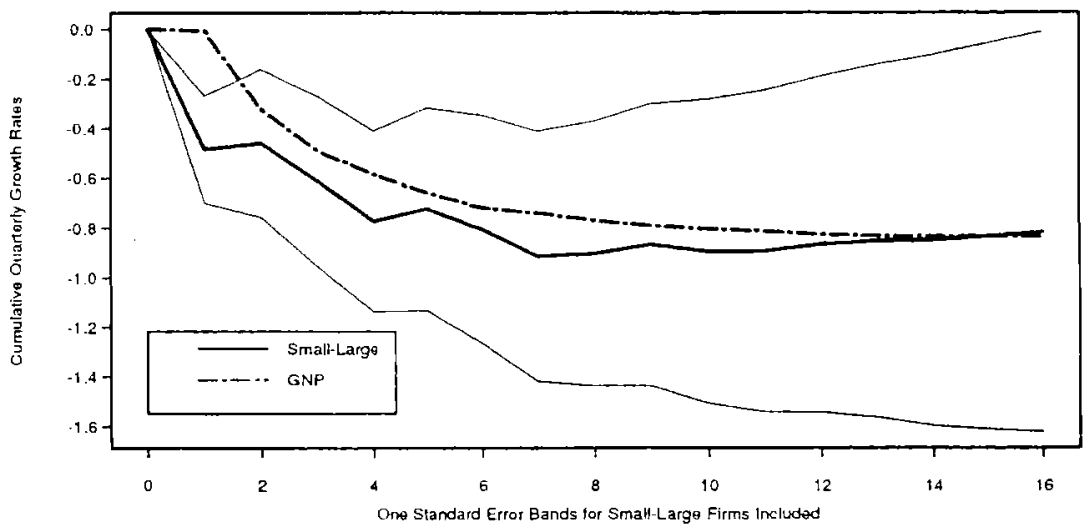

Figure 8

impulse Response of the Difference in Sales Growth to an Increase in Real GNP Growth

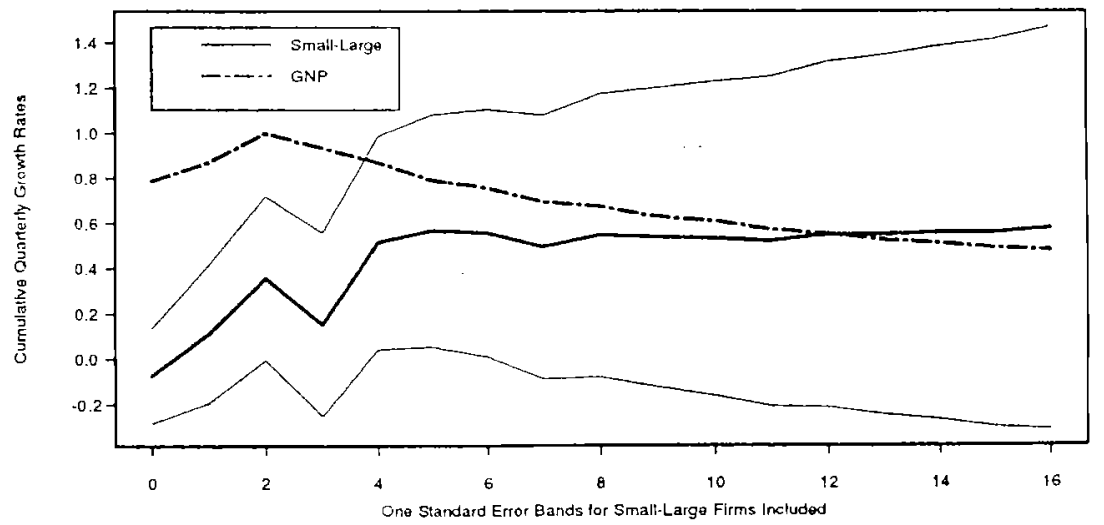


Figure 9

95\% Conficience Intervals for Romer Dummy Coefficients, VAR without FFR

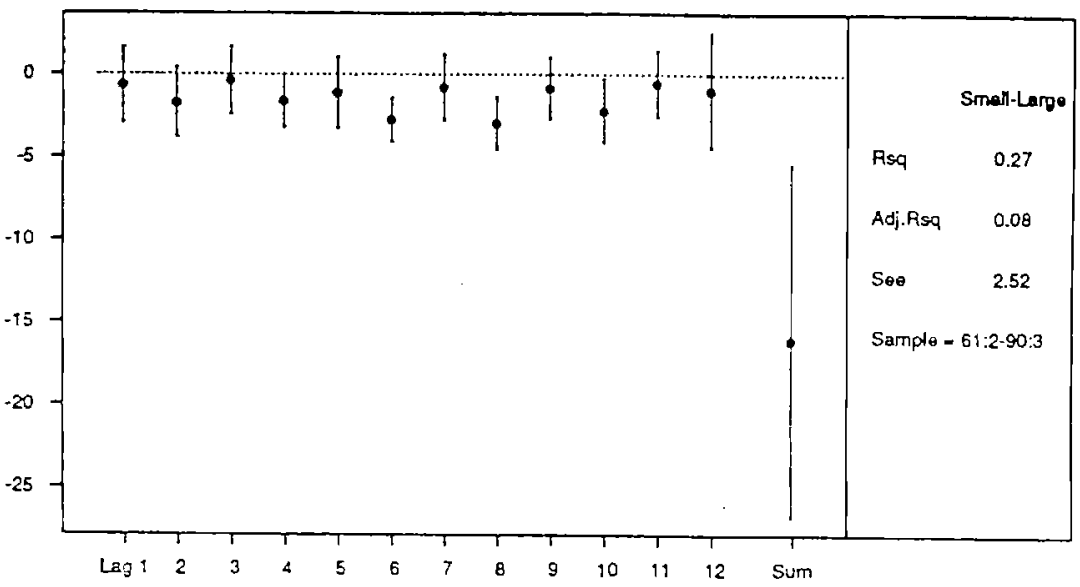

Figure 10

95\% Confidence Intervals for Romer Dummy Coefficients, VAR with FFR

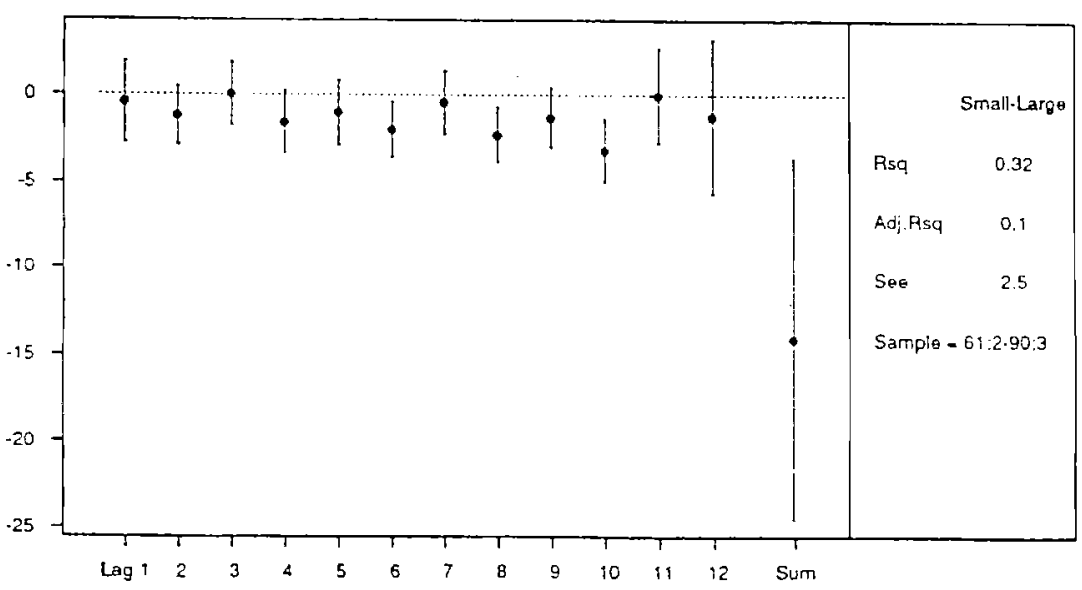


Figure 11

Impulse Response of Difference in Sales Growth to a Romer Episode

VAR with Small-Large Firm Sales Growth, GNF Growth, and Inflation

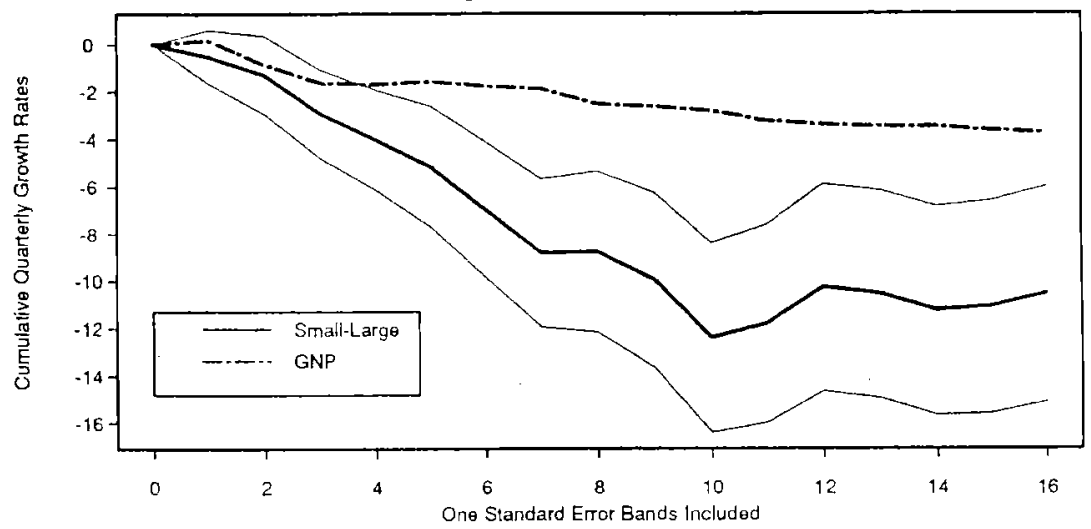

Figure 12

Impulse Response of Difference in Sales Growth to a Romer Episode VAP with Small-Large Sales Growth. GNP Growth, Inflation, and Funds Rate

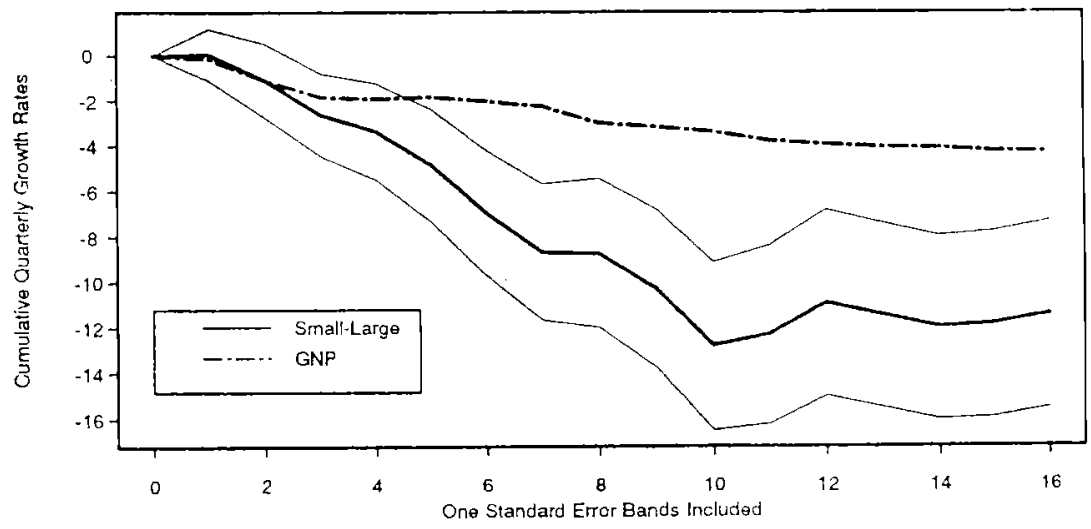


Figure 13

Impulse Response of Bank Debt to FFR

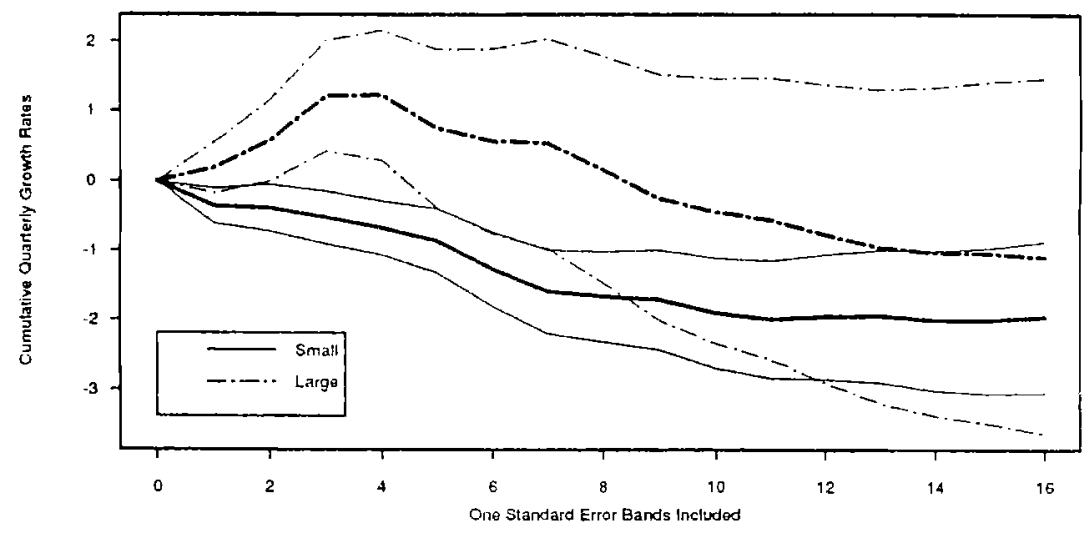

Figure 14

Impulse Response of the Bank Debt/Sales Ratio to FFR

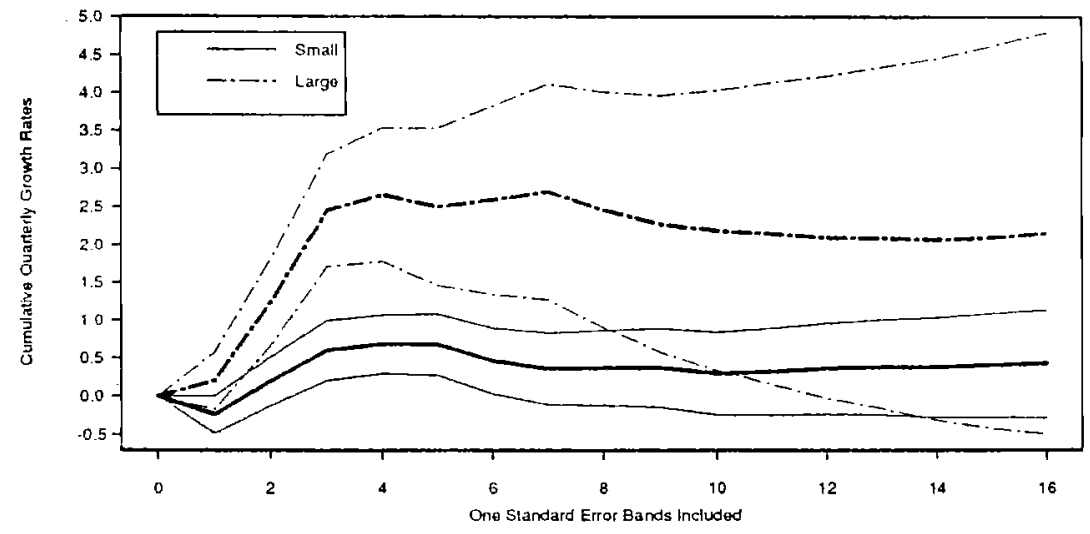


Figure 15

Growth Rate in Real Sales

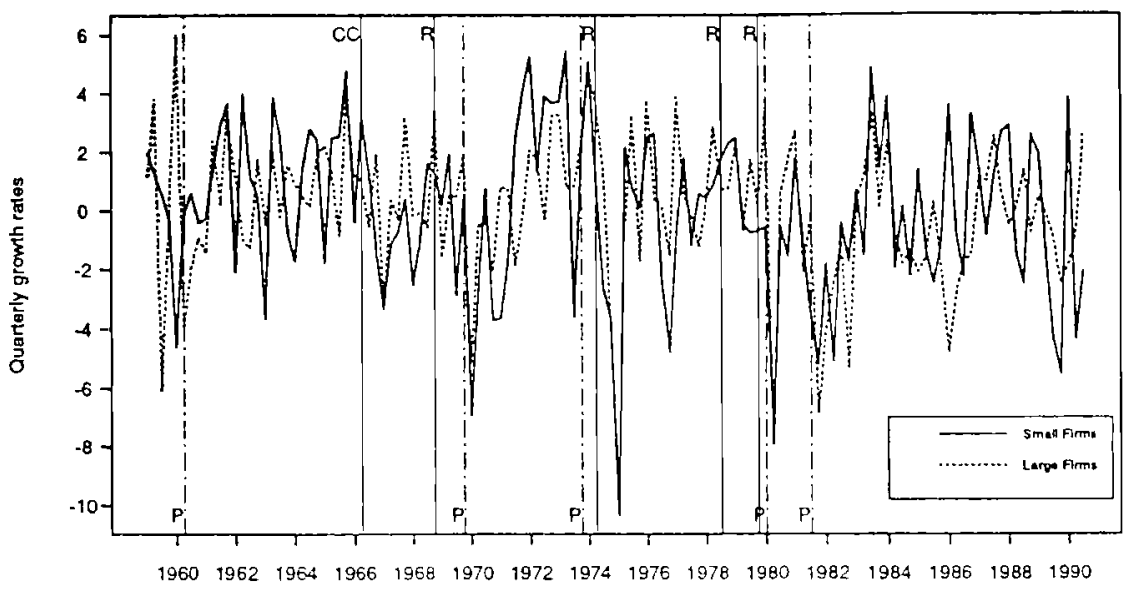

Smoothed Growth Rate in Real Sales

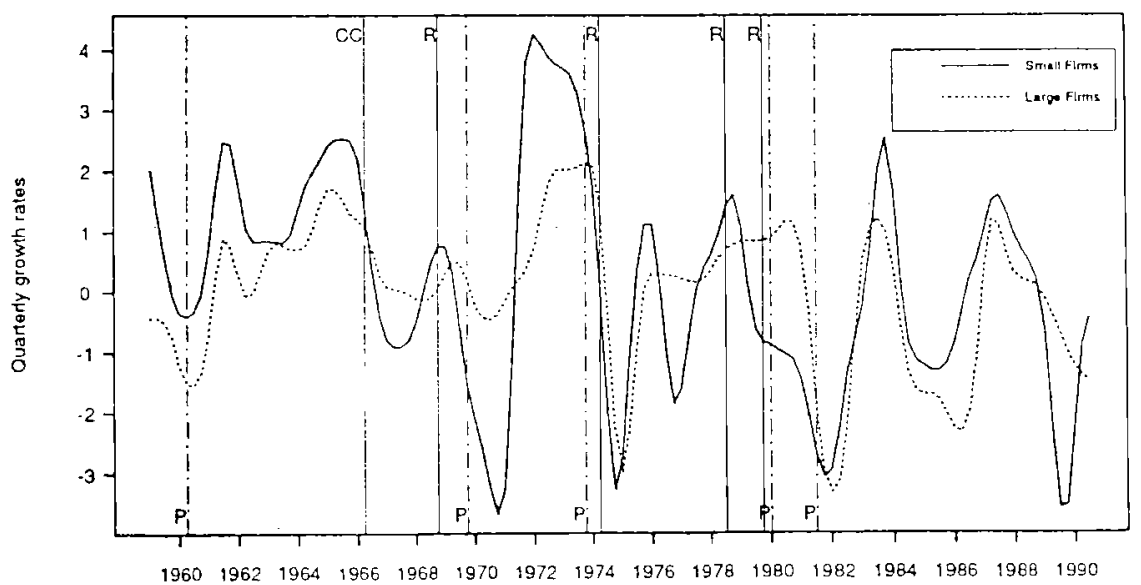


Figure 16

Growth Rates for Small and Large Firms, 1988:Q1-1991:Q1

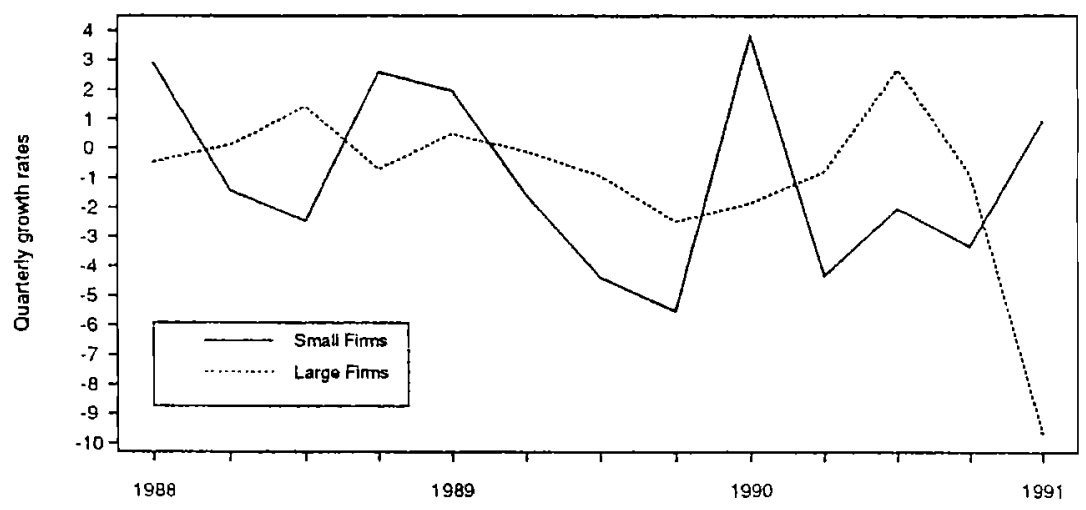

Smoothed Growth Rates for Small and Large Firms, 1988:Q1-1991:Q1

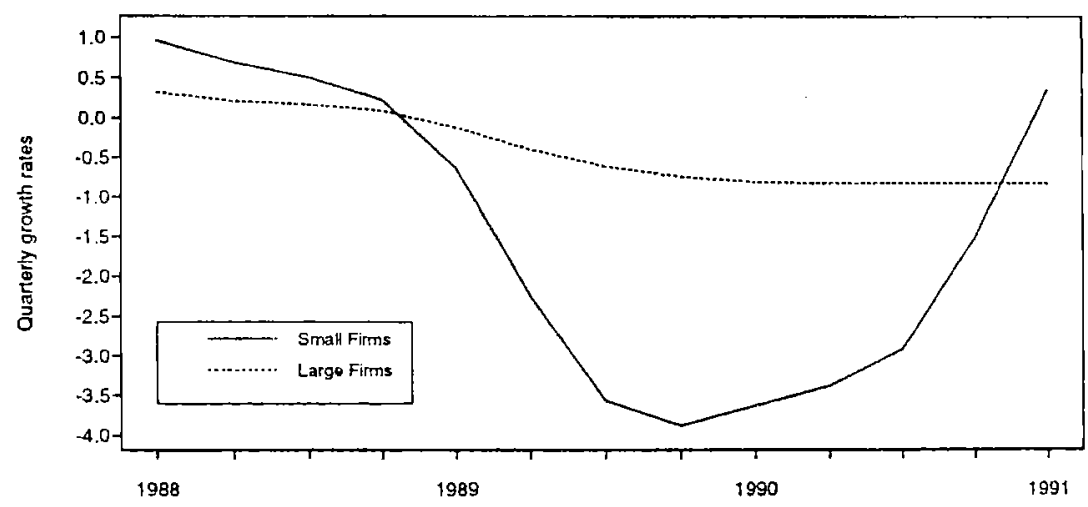


Figure 17

Monetary Policy Indicators, 1988:Q1-1991:Q1
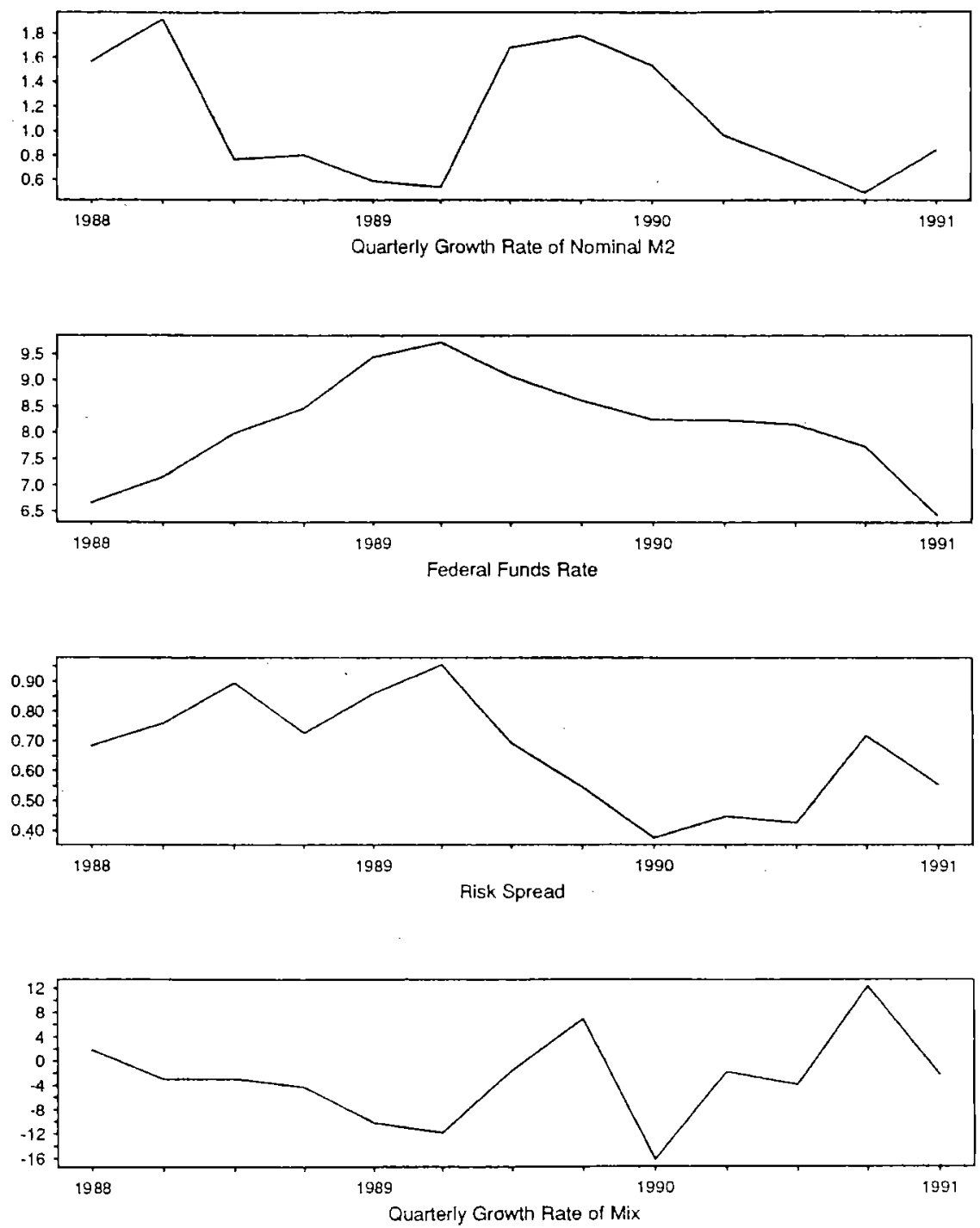